OPEN ACCESS

Edited by:

Abhay K. Pandey,

Allahabad University, India

Reviewed by:

Haripriya Vittal Rao,

Wake Forest Baptist Medical Center,

United States

Wen-Chi Wei,

National Research Institute of Chinese

Medicine, Taiwan

*Correspondence:

Xiangwei Chang

chxwing@ahtcm.edu.cn

Qin Zhang

zhaqin01@163.com

${ }^{\dagger}$ These authors have contributed equally to the work

Specialty section:

This article was submitted to

Ethnopharmacology,

a section of the journal

Frontiers in Pharmacology

Received: 15 October 2020

Accepted: 15 December 2020

Published: 14 January 2021

Citation:

Yang L, Chen Y, Liu Y, Xing Y, Miao C, Zhao $Y$, Chang $X$ and Zhang $Q$ (2020)

The Role of Oxidative Stress and

Natural Antioxidants in Ovarian Aging.

Front. Pharmacol. 11:617843

doi: 10.3389/fphar.2020.617843

\section{The Role of Oxidative Stress and Natural Antioxidants in Ovarian Aging}

\author{
Liuqing Yang ${ }^{1 \dagger}$, Yun Chen ${ }^{1 \dagger}$, Yan Liu ${ }^{2 \dagger}$, Yu Xing ${ }^{3,4}$, Chenyun Miao ${ }^{1}$, Ying Zhao ${ }^{1}$, \\ Xiangwei Chang ${ }^{5 *}$ and Qin Zhang ${ }^{1 *}$
}

${ }^{1}$ Guangxing Hospital Affiliated to Zhejiang Chinese Medical University, Hangzhou, China, ${ }^{2}$ The 2nd Clinical Medical College, Zhejiang Chinese Medical University, Hangzhou, China, ${ }^{3}$ Brigham and Women's Hospital and Harvard Medical School, Boston, MA, United States, ${ }^{4}$ Dongfang Hospital, Beijing University of Chinese Medicine, Beijing, China, ${ }^{5}$ College of Pharmacy, Anhui University of Chinese Medicine, Hefei, China

The ovarian system comprises vital organs in females and is of great significance for the maintenance of reproductive potential and endocrine stability. Although complex pathogenesis undoubtedly contributes to ovarian aging, increasing attention is being paid to the extensive influence of oxidative stress. However, the role of oxidative stress in ovarian aging is yet to be fully elucidated. Exploring oxidative stress-related processes might be a promising strategy against ovarian aging. In this review, compelling evidence is shown that oxidative stress plays a role in the etiology of ovarian aging and promotes the development of other ovarian aging-related etiologies, including telomere shortening, mitochondrial dysfunction, apoptosis, and inflammation. In addition, some natural antioxidants such as quercetin, resveratrol, and curcumin have a protective role in the ovaries through multiple mechanisms. These findings raise the prospect of oxidative stress modulator-natural antioxidants as therapeutic interventions for delaying ovarian aging.

Keywords: oxidative stress, natural antioxidants, anti-ovarian aging, reactive oxygen species, mitochondria, inflammation, apoptosis, telomeres

\section{INTRODUCTION}

Dreams of longevity are as old as humanity itself. Over the past decades, human longevity has increased substantially worldwide. It is predicted that approximately $22 \%$ of the global population will be older than 60 by 2050 (Bellantuono, 2018). Consequently, age-related diseases, such as cognitive impairment, cardiovascular diseases, and cancer are markedly increasing and are the leading cause of death and reduced quality of life (Franceschi et al., 2018a).

Ovarian state influence the health of all phases of life and are the main determinants of female life span (de Kat et al., 2016; Rajkovic and Pangas, 2017; Mason et al., 2018; Quinn and Cedars, 2018; Tsiligiannis et al., 2019). Ovarian aging, which occurs earlier than the aging of most other organs, is a continuous process starting from the oocyte death of the embryo at 20 weeks of gestation. (Amanvermez and Tosun, 2016). The most significant characteristic of ovarian aging is a diminished ovarian reserve (DOR), i.e., the decline in the quality and quantity of oocytes, which is also the main reason for infertility and failure in assisted reproductive technology (ART) (MayPanloup et al., 2016). Moreover, ovarian aging is associated with an increased risk for diabetes, heart disease, cancer, and other age-related conditions. The importance of the ovary in maintaining health and extending lifespan has also been well demonstrated in animal models. Transplanting the ovaries of young mice into old mice can prolong the life span of the old mice (Mason et al., 2018). Cardioprotective benefits, cognitive behavior, and immune and renal functions can be positively 
restored by re-establishment of active ovarian function in aged female mice (Mason et al., 2011; Parkinson et al., 2017; Peterson et al., 2017). Therefore, keeping the ovaries "young" is critical.

Several theories have been proposed to explain the mechanism underlying ovarian aging, including free radical theory, apoptosis, telomere shortening, mitochondrial dysfunction, and inflammation theory (Shi et al., 2016; Regan et al., 2018a; Huang Y et al., 2019; Kasapoğlu and Seli, 2020; Wang et al., 2020). Free radical theory, a classical theory of aging, proposes that oxidative stress caused by elevated intracellular levels of reactive oxygen species (ROS) is the most significant contributor to cellular senescence and aging in mammals (Liochev, 2013; Zhang $\mathrm{H}$ et al., 2015). Furthermore, numerous studies have documented that oxidative stress is a leading driver of the ovarian aging process and promotes the development of other ovarian aging-related etiologies, such as telomere shortening, mitochondrial dysfunction, apoptosis, and inflammation (Lim and Luderer, 2011; Arulselvan et al., 2016; Bauer et al., 2017; Prasad et al., 2017; Takeo et al., 2017; Huang ML et al., 2019; Sasaki et al., 2019; Pineda-Pampliega et al., 2020). The role of oxidative stress is also becoming increasingly evident in the pathogenesis of a diverse range of pathological conditions, including Alzheimer's disease, cardiometabolic diseases, cancer, diabetes mellitus, and retinal dystrophies (Niemann et al., 2017; Saha et al., 2017; Butterfield and Boyd-Kimball, 2018; Cioffi et al., 2019; Domènech and Marfany, 2020; Yaribeygi et al., 2020).

Based on these theoretical considerations, alleviating oxidative stress in the ovaries is an important means of delaying ovarian aging. Effective natural antioxidants could provide novel and safe interventional strategies to delay or prevent ovarian aging and related diseases. Despite a series of reports regarding the antioxidative effects of natural products on ovarian aging, to date, there are no related systematic reviews in the literature. In this review, the underlying mechanism of oxidative stress during ovarian aging and the molecular protective mechanisms of natural antioxidants in anti-ovarian aging are comprehensively explored.

\section{OVERVIEW OF OXIDATIVE STRESS IN OVARIAN AGING}

ROS, including both free radical and non-free radical, oxygenated molecules, such as superoxide radicals $\left(\mathrm{O}_{2} \bullet-\right), \mathrm{H}_{2} \mathrm{O}_{2}$, hydroxyl radicals $(\bullet \mathrm{OH})$, and singlet oxygen $\left({ }^{1} \mathrm{O}_{2}\right)$, are mostly generated continuously as byproducts during common metabolic processes in eukaryotic cells (Liguori et al., 2018). They all contain oxygen atoms and have strong oxidizing abilities. A few reviews summarized the pathophysiological functions of ROS (Sugino, 2005; Dizdaroglu and Jaruga, 2012; Rizzo et al., 2012; Kamat et al., 2016; Lu et al., 2018). At low levels, ROS widely participate in cell signal transduction and promote cell survival, proliferation, and differentiation (Rizzo et al., 2012; Lu et al., 2018). ROS are also physiological regulators of ovarian processes and play a key role in follicular development and survival (Sugino, 2005). However, heightened levels of ROS, which overpower cellular antioxidant and repair capacities, can trigger oxidative stress in cells, directly causing oxidative damage to all biomolecules within the cellular environment (including proteins, lipids, and DNA), and thus contribute to the development of aging and related diseases (Dizdaroglu and Jaruga, 2012; Kamat et al., 2016).

Oxidative stress, caused by the imbalance between the production and destruction of ROS, directly damages the intraovarian environment, just as it does in many other cells. Moreover, all primary oocytes are formed by the fifth month of fetal life and remain dormant before complete meiosis I, a decades-long process rendering the oocyte susceptible to chronic oxidative insult (Peters et al., 2020). To date, several studies have shown that the accumulation of ROS in the ovaries deteriorates oocyte quality, induces granulosa cell (GC) apoptosis, and accelerates degeneration of the corpus luteum (Chaube et al., 2014; Tiwari et al., 2015; Prasad et al., 2016; Wang S. et al., 2017; Yang et al., 2017; Sohel et al., 2019). Furthermore, it decreases communication between oocytes and GCs, affecting preovulatory oocyte maturation (Cajas et al., 2020). Oxidative damage to the ovary is generally caused by the propagation of lipid peroxidation cascades, which seriously influences folliculogenesis, meiosis, and ovulation, and eventually leads to ovarian aging (Lim and Luderer, 2011; Edrey and Salmon, 2014; Maclaran and Nikolaou, 2019).

The level of intra-ovarian ROS has been confirmed to be positively correlated with female age, which also makes the female germline particularly vulnerable to the cumulative effects of chronic oxidative stress (Lim and Luderer, 2011; Takeo et al., 2017; Sasaki et al., 2019). Age-related increases in ROS have been found in the follicular fluid and oocytes of women undergoing ART. Among these elderly women with high ROS levels, the success rate of ART is relatively low (Oyawoye et al., 2003; Wiener-Megnazi et al., 2004). In contrast, the content of antioxidants in the intraovarian environment is reduced with age, which means there is a diminished ability to scavenge ROS. Superoxide dismutases (SODs) and catalase (CAT) are the major endogenous antioxidant defense systems against ROS (Racchi, 2013; Ighodaro and Akinloye, 2018). Clinical studies have shown that the mRNA and protein levels of the aforementioned antioxidants in GCs of elderly women undergoing in vitro fertilization (IVF) were significantly lower than those of younger women. The elderly group also showed abnormal mitochondrial morphology and fewer lipid droplets at the ultrastructural level (Tatone et al., 2006). In addition, Matos et al. presented evidence that SOD activity and SOD1 levels in cumulus cells surrounding ovulated oocytes decreased remarkably with female age, and low SOD activity is related to unsuccessful IVF outcomes (Matos et al., 2009). In conclusion, the imbalance between ROS and antioxidants leads to a decline in oocyte quality, which is an important factor affecting the success of ART and is implicated in the aging process of the ovaries.

In addition to direct damage to the ovaries, oxidative stress can also promote the development of other ovarian aging-related mechanisms, including telomere shortening, mitochondrial dysfunction, inflammation, and apoptosis. 


\section{EFFECTS OF OXIDATIVE STRESS ON TELOMERES IN THE OVARIES}

\section{Telomeres and Ovarian Aging}

Telomeres, the dynamic nucleoprotein-DNA structures present at both ends of each chromosome, are responsible for maintaining genome integrity and chromosome stability (Zhang et al., 2018). The length of telomeres shortens progressively with each cell division (mitosis) and is strongly associated with lifespan (Heidinger et al., 2012; Turner et al., 2019). Excessive shortening triggers persistent DNA damage response or genomic instability, causing cellular senescence, and is also strongly linked to lifespan (Whittemore et al., 2019; Smith et al., 2020). Recently, the correlation between the telomere status of ovarian cells and the human female reproductive lifespan has drawn growing attention. A crosssectional study indicated that the lack of human GC telomerase activity was associated with occult ovarian insufficiency (Butts et al., 2009). Additionally, shortened telomere length and diminished telomerase activity in GCs have also been associated with primary ovarian insufficiency (POI), thereby serving as potential molecular markers for the progression of ovarian function decline (Xu X et al., 2017). Telomere length in cumulus cells is positively correlated with oocyte and embryo quality (Cheng et al., 2013). Consistent with this, Keefe et al. found that in IVF, the pregnancy rate is higher in women with longer oocyte telomere length than in those with shorter oocyte telomere lengths (Keefe et al., 2007).

\section{Oxidative Stress and Telomeres in the Ovaries}

A few reviews summarized that telomeres intrinsically comprise hundreds of guanine bases, which is most easily oxidized by ROS because they have the lowest redox potential amongst the DNA bases (Tardat and Déjardin, 2018). Furthermore, telomere oxidative lesions are less efficiently repaired because of the telomere heterochromatin state, suggesting that telomeres are most vulnerable to oxidative damage (Smith, 2018; Coluzzi et al., 2019; Singh et al., 2019). Accordingly, oxidative stress is considered to be the main cause of telomere shortening (Erusalimsky, 2020). Cigarette smoke, a source of exogenous pro-oxidants, has been confirmed to be associated with increased oxidative stress in the ovary (Sobinoff et al., 2013; Mai et al., 2014; Kim et al., 2018; Li et al., 2020). Related studies have shown that mice exposed to chronic cigarette smoke condensate or smoke exhibited increased egg fragmentation, delayed fertilization, increased apoptosis in blastocysts, and shortened telomeres in embryos (Huang et al., 2009; Dechanet et al., 2011). Furthermore, another study found that the smoke component-induced oxidative damage is greatly reduced by the antioxidant, N-acetylcysteine (NAC) (Huang et al., 2010). It has also been confirmed that increased ROS levels in oocytes result in telomere shortening and reduced developmental competence of aged oocytes (Sasaki et al., 2019). ROS levels are lower, and telomeres are longer, in oocytes from young females (6-8 weeks of age) than in those from reproductively aged female mice
(42-48 weeks of age) (Yamada-Fukunaga et al., 2013). In summary, as an important factor of aging, oxidative stress can also mediate telomere damage in the ovaries and cause ovarian aging (Figure 1).

\section{EFFECTS OF OXIDATIVE STRESS ON MITOCHONDRIA IN THE OVARIES}

\section{Mitochondria and Ovarian Aging}

Growing evidence suggests that there is a close relationship between mitochondria and ovarian aging (May-Panloup et al., 2016; Wang $T$ et al., 2017; Kasapoğlu and Seli, 2020). Mitochondria act as energy factories for cells, providing energy and regulating cellular signaling pathways for oocyte maturation, fertilization, and embryogenesis through aerobic respiration (Zhang et al., 2017; Harvey, 2019). Studies have shown that blocking adenosine triphosphate (ATP) synthase prevents germ stem cells from developing into oocytes (Teixeira et al., 2015). Unlike Mendelian inheritance, mitochondrial DNA (mtDNA) is derived exclusively from maternal egg cells (Lutz-Bonengel and Parson, 2019). The mtDNA copy number of oocytes, GCs, and cumulus cells are being explored as predictors of oocyte quality and embryo viability (Wells, 2017; Cecchino and Garcia-Velasco, 2019). Ovarian aging is related to reduced oocyte mtDNA content, and studies have shown that the mtDNA copy number per oocyte of young women is significantly higher than that of aged women or those of the same age with DOR (Pasquariello et al., 2019). In addition, the accumulation of female mouse germline mtDNA mutations exacerbates ovarian aging and reduces lifespan (Ross et al., 2014; Yang et al., 2020). Evidence for this is that the mitochondrial content of GCs and oocytes was significantly decreased in a mouse model of fragile $\mathrm{X}$ primary ovarian insufficiency (Conca Dioguardi et al., 2016). Therefore, reproductive experts proposed that mitochondrial transplantation might be a novel possibility for rejuvenating oocyte quality and overcoming age-related infertility or recurrent IVF failure (Kristensen et al., 2017; Labarta et al., 2019). In humans as well as in other animal species, the transfer of autologous or heterologous mitochondria has been proven to improve oocyte quality and IVF outcomes (Hua et al., 2007; Oktay et al., 2015; Srirattana and St John, 2018). Therefore, mitochondria have multiple effects on ovarian aging.

\section{Oxidative Stress and Mitochondria in the Ovaries}

Mitochondria produce energy to drive the cell's biochemical reactions. In addition, they are also the main source of ROS based on electron leakage from the respiratory chain (Scialò et al., 2017). However, paradoxically, mtDNA, because of the lack of protection by histones or DNA-binding proteins, is particularly vulnerable to ROS-mediated damage (Aryaman et al., 2017; Kauppila et al., 2017; Kaarniranta et al., 2019). Moreover, the ROS generation sites overlap with mtDNA positions, which are mainly attached to the matrix side of the inner mitochondrial 


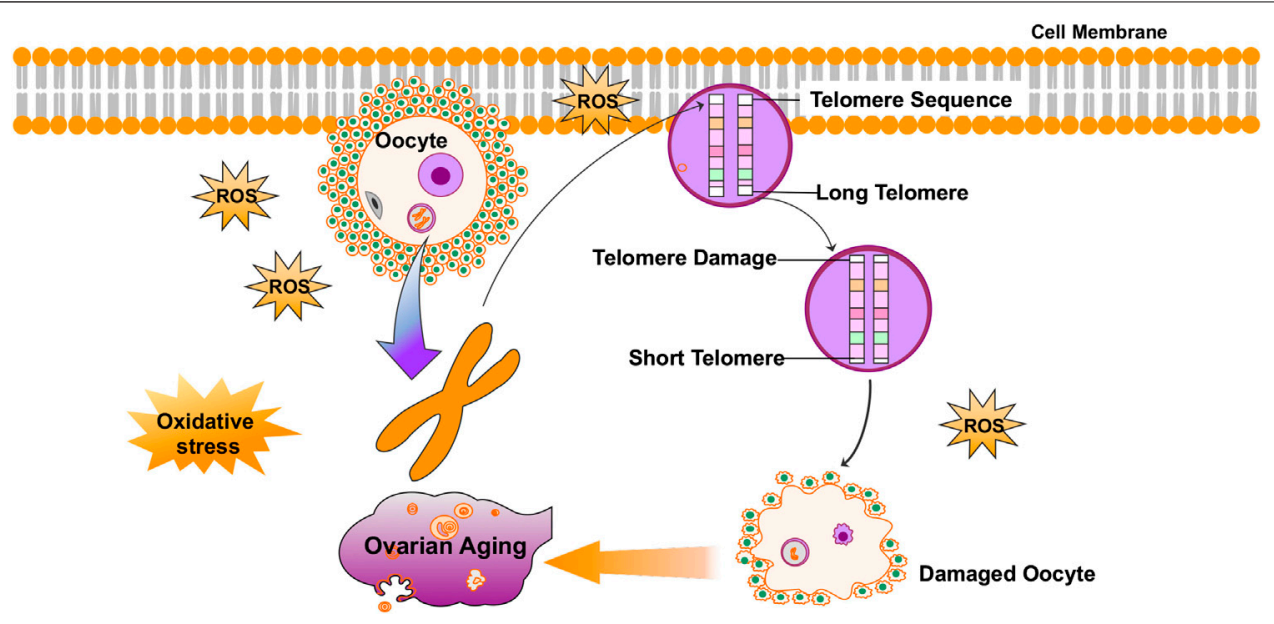

FIGURE 1 | Oxidative stress mediates telomere damage in the ovaries and causes ovarian aging.

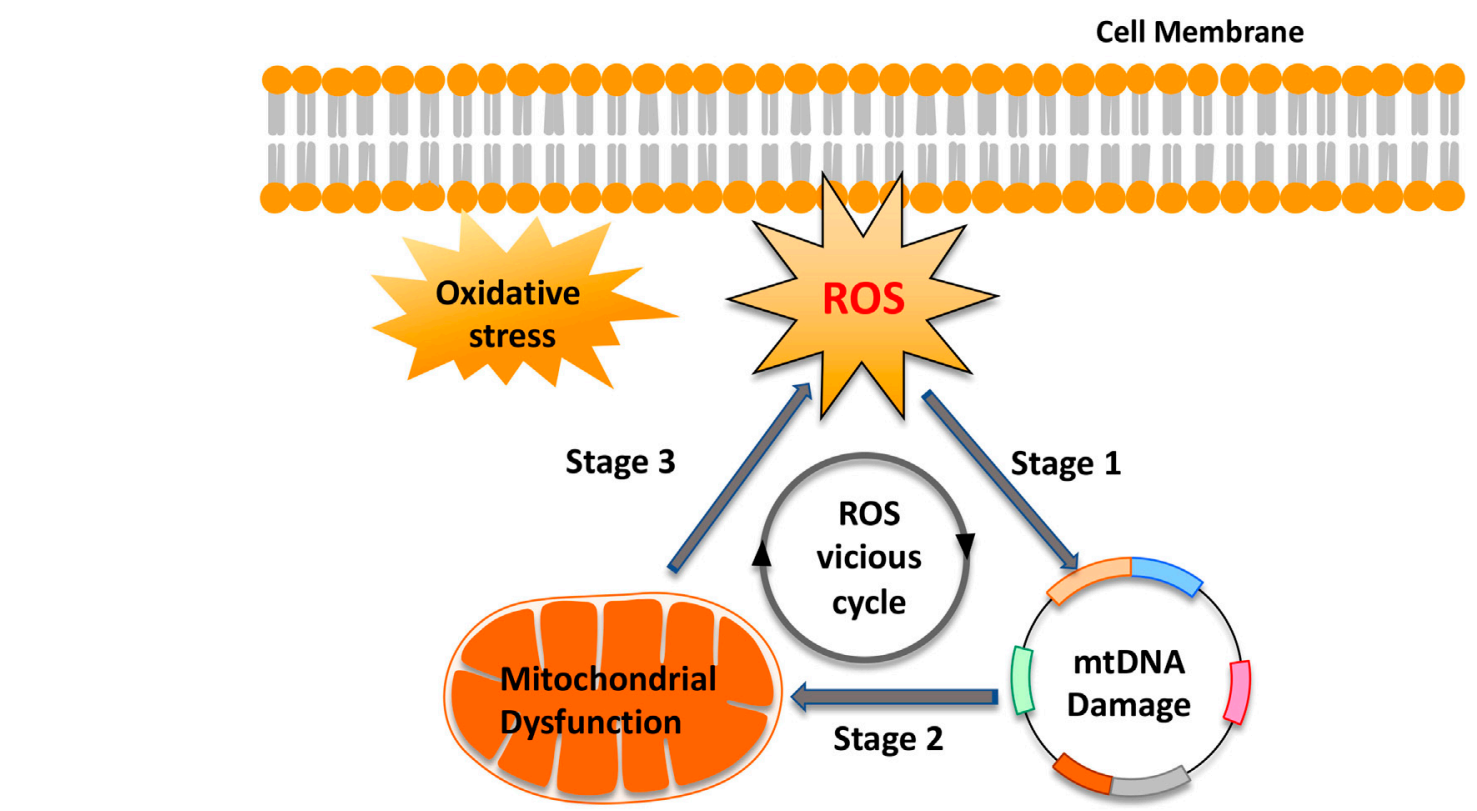

FIGURE 2 | "Reactive oxygen species (ROS) vicious cycle" of ROS production, mtDNA damage, mitochondrial dysfunction, and further ROS production. The cycle implies an exponential growth of ROS production and mtDNA mutagenesis.

membrane (Murphy, 2012). This condition creates an opportunity to form mtDNA-protein crosslinks mediated by ROS, which increases mitochondrial fission and exacerbates mtDNA damage (Caston and Demple, 2017; Yang S.-G. et al., 2018). In turn, mtDNA damage and mutagenesis are directly responsible for a gradual impairment of the respiratory chain function and thus increase electron leakage and ROS production in the mitochondria. This "ROS vicious cycle" (Figure 2), present in different tissues and cells, causes exponentially accelerating oxidative stress with age (Pinto and Moraes, 2015). Consistent with this theory, Aitken et al. confirmed that in MII mouse oocytes, oxidative stress-catalyzed lipid peroxidation could initiate cyclic ROS transmission by directly destroying mitochondrial components (Lord et al., 2015). Studies also confirmed that exposure of mouse MII oocytes to exogenous $\mathrm{H}_{2} \mathrm{O}_{2}$ resulted in the dissipation of mitochondrial membrane potential, a decrease in cytoplasmic ATP levels, and the disruption of meiotic spindles (Zhang et al., 2006). However, $\mathrm{H}_{2} \mathrm{O}_{2}$-induced damage to mouse oocytes was ameliorated by supplementation with the antioxidant, NAC (Zhang et al., 2006). In addition, oxidative stress-induced cytochrome c (Cyt c) release from mitochondria, by changing the mitochondrial membrane potential, activates the apoptosis cascade (RedzaDutordoir and Averill-Bates, 2016). 


\section{EFFECTS OF OXIDATIVE STRESS ON INFLAMMATION IN THE OVARIES}

\section{Inflammation and Ovarian Aging}

Inflammation is associated with the pathogenesis of human aging (López-Otín et al., 2013; Franceschi et al., 2018b; Chung et al., 2019). This is also the case in the ovaries. Recent studies have shown that inflammation is a key marker of the aging ovarian stroma and is considered a new mechanism of POI (Huang et al., 2019b; Navarro-Pando et al., 2020). Clinical studies in humans have shown that inflammatory marker levels are associated with the risk of POI or early menopause. Ylmaz et al. detected the levels of serum inflammatory marker levels in patients with POI and normal fertile women, and found that the neutrophil-tolymphocyte ratio (NLR) was significantly lower in the POI group than in the normal fertility group, and multivariate logistic regression analysis showed that NLR $\leq 1.5$ was an independent risk factor for POI (Yldrm et al., 2015). Yue et al. also found that compared to the control group, the serum levels of interleukin (IL)-6 and IL-21 in the primary ovarian failure (POF) group were significantly higher (Sun et al., 2018). Chronic inflammation triggered by obesity might impair oocyte meiosis and oocyte quality (Snider and Wood, 2019). Consistent with these results, Whitcomb et al. found that early menopause cases had higher tumor necrosis factor receptor 2 (TNFR2) levels than controls (Bertone-Johnson et al., 2019). The concentration of TNFR2 was strongly related to TNFa and had the function of regulating TNFa activity (Yang $S$ et al., 2018). Studies in animal models demonstrated that TNFa knockout mice had higher levels of GC proliferation, less incidence of follicle atresia, and higher fertility than wild-type mice (Cui et al., 2011). Therefore, inflammation also plays an important role in ovarian aging.

\section{Oxidative Stress and Inflammation in the Ovaries}

Numerous studies have revealed that there is a strong association between inflammation and oxidative stress. They seem to accompany one another and promote each other in many chronic diseases (Li S et al., 2016; Biswas, 2016; Steven et al., 2019; Zuo et al., 2019). ROS may serve as a "kindling" to activate NLRP3 inflammasomes, leading to pro-inflammatory cytokine secretion (IL-1 $\beta$ and IL-18) (Abais et al., 2015; Long et al., 2020). ROS may also induce the activation of nuclear factor kappa $B$ $(\mathrm{NF}-\kappa \mathrm{B})$, a crucial mediator of inflammatory responses, and is associated with the pathogenesis of many disorders (Liu $\mathrm{T}$ et al., 2017; Liang et al., 2017; Qin et al., 2017). In addition, the inflammatory agents interferon (IFN) $-\gamma$ and lipopolysaccharides (LPS) synergistically increase both extracellular and intracellular ROS production in human pancreatic cancer cells (Wu et al., 2013). Furthermore, studies have demonstrated that TNFa, IL- $1 \beta$, and IFN- $\gamma$ induce ROS production in multiple types of human cells (Yang et al., 2007; Agharazii et al., 2014). Similarly, increased levels of proinflammatory factors and oxidative products have been observed in animal POI models induced by chemotherapy drugs or radiotherapy, and antioxidats can simultaneously reduce pro-inflammatory factors (TNF $\alpha$, IL-6, and IL-10) and oxidative product (malondialdehyde (MDA), $\mathrm{H}_{2} \mathrm{O}_{2}$, and ROS) levels by activating $\mathrm{PI} 3 \mathrm{~K} / \mathrm{AKT} / \mathrm{mTOR}$ or inhibiting NF- $\kappa \mathrm{B}$ signaling pathways, thereby improving ovarian function $(\mathrm{He}$ et al., 2017; Liu C et al., 2018; Li and Liu, 2018; Jiang et al., 2019). In summary, oxidative stress can promote inflammation in the ovaries and cause ovarian aging (Figure 3 ).

\section{EFFECTS OF OXIDATIVE STRESS ON APOPTOSIS IN THE OVARIES}

\section{Apoptosis and Ovarian Aging}

Apoptosis plays an important role in germ cell depletion in the mammalian ovaries (Tiwari et al., 2015). Follicular atresia caused by GC apoptosis is the primary process responsible for the loss of follicles and oocytes in the mammalian ovary and is one of the pathogenic mechanisms of premature ovarian failure (Krysko et al., 2008; Regan et al., 2018a; Regan et al., 2018b). Excessive GC apoptosis may deprive follicular oocytes of nutrients, maturationenabling factors, and survival factors, and thus directly lead to follicular death (Regan et al., 2018a). Clinic studies have shown that higher mural GC apoptosis is correlated with decreased ovarian reserves, fewer oocytes retrieved, and a lower rate of highquality embryos as well as with age (Sadraie et al., 2000; Fan et al., 2019). Consistent with this, Ebner et al. reported that the apoptotic GCs in younger patients ( $\leq 35$ years) were significantly fewer than in older ones, and the processes of apoptosis seems to impair oocyte and gamete maturation (Corn et al., 2005). Animal experiments also provide strong evidence that the ovarian phenotype, including reduced ovulation rate and a dramatic decline in fertility, observed in hyh mutant (Napahyh/hyh) mice is based on an increased rate of apoptosis in GCs and follicular atresia (Arcos et al., 2017).

\section{Oxidative Stress and Apoptosis in the Ovaries}

Accumulating evidence shows that oxidative stress is one of the key factors that induces oocyte and GC apoptosis in mammals (Prasad et al., 2016; Tiwari et al., 2016). To date, research indicates that there are two main pathways of oocyte and GC apoptosis caused by oxidative stress: the extrinsic (death receptor) pathway and the intrinsic (mitochondrial) pathway (Figure 4) (Regan et al., 2018a; Yadav et al., 2018). First, oxidative stress can induce the activation of mitochondrial pathways. Excessive ROS may change the mitochondrial membrane potential (MMP) by regulating the ratio of pro-/anti-apoptosis factors, which leads to the release of Cyt $\mathrm{c}$ from the mitochondria into the cytosol (Circu and Aw, 2010; Tripathi et al., 2013; Premkumar and Chaube, 2015). Cyt c further binds to apoptotic protease-activating factor 1 (APAF1), causing activation of caspase-9 (Monian and Jiang, 2012; Xiong et al., 2014). The effector, caspase-3, executes the final steps of apoptosis and cleaves various structural and regulatory proteins in female germ cells (Xiong et al., 2014). Li et al. demonstrated that oxidative stress induced bovine GC apoptosis by increasing the expression of cleaved caspase- 3 


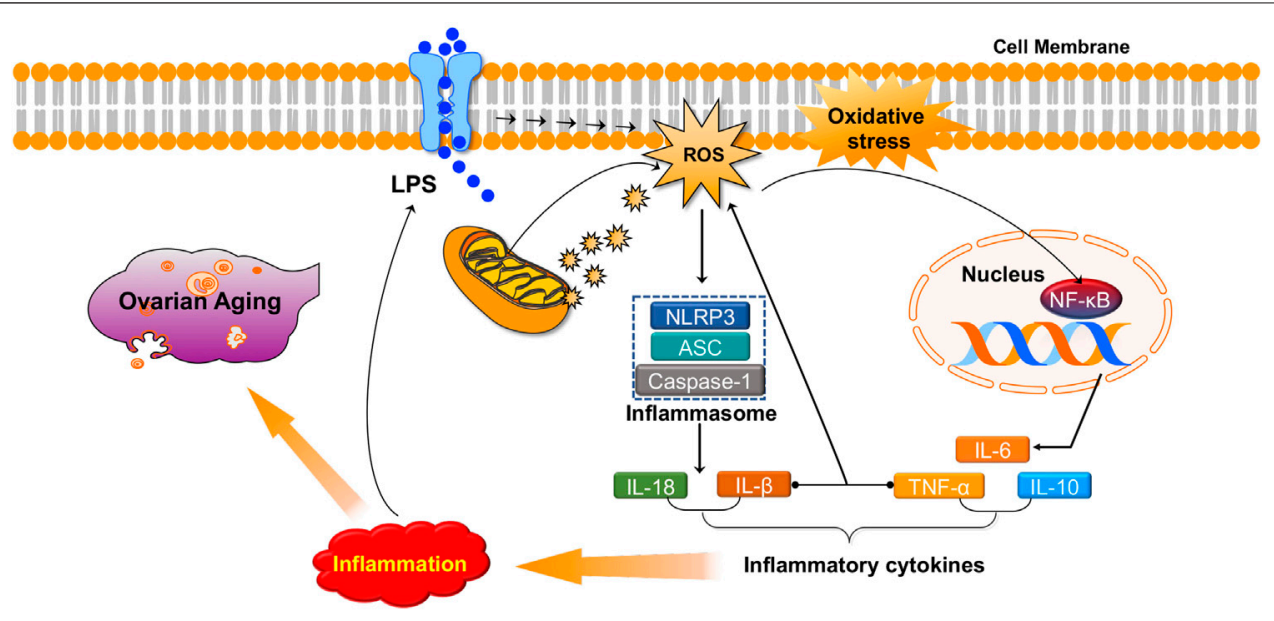

FIGURE 3 | Oxidative stress promotes inflammation in the ovaries and causes ovarian aging.

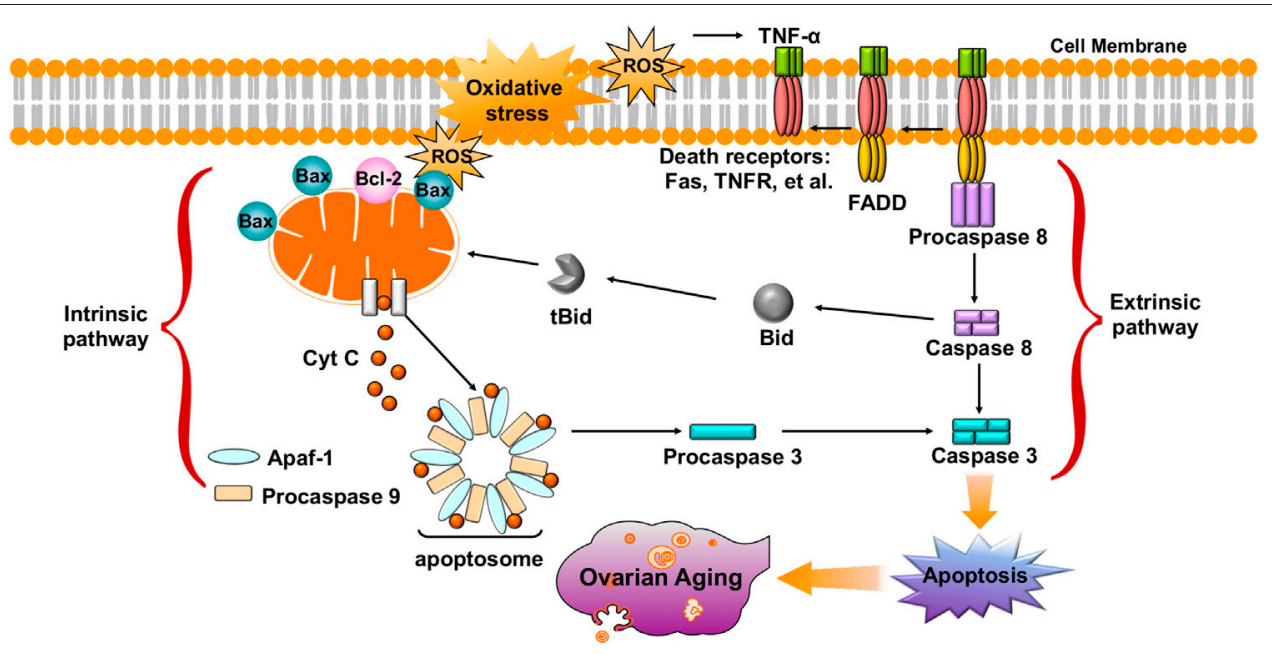

FIGURE 4 | Oxidative stress leads to oocyte and GC apoptosis, and causes ovarian aging via extrinsic (death receptor) pathway and intrinsic (mitochondrial) pathway.

and the $\mathrm{Bax} / \mathrm{Bcl}-2$ ratio as well as decreasing the expression of antioxidant enzymes (SOD2, glutathione peroxidase (GSH-Px)) (Wang $\mathrm{Y}$ et al., 2019). In addition, excessive ROS in oocytes and GCs can induce the release of TNFa (Kong et al., 2018; Miao et al., 2018). TNF- $\alpha$ binds to its death receptors (such as Fas and TNFR) and then activates the death receptor (extrinsic) pathway of apoptosis through Fas-associated death domain-dependent activation of caspase-8 (Morgan et al., 2008; Guicciardi and Gores, 2009; Redza-Dutordoir and Averill-Bates, 2016). Moreover, activated caspase- 8 can also cleave Bid, which then causes the release of Cyt $c$ from mitochondria and activates a crosstalk pathway between death receptors and mitochondria (Huang et al., 2016). Another study found that NAC counteracted $\mathrm{H}_{2} \mathrm{O}_{2}$-induced GC apoptosis via the ROS-JNK-p53 pathway, suggesting a functional role of ROS during this process (Yang et al., 2017). Therefore, protecting female germ cells against oxidative stress-induced apoptosis might be of great therapeutic value in the treatment of ovarian aging.

\section{NATURAL ANTIOXIDANT-BASED INTERVENTIONS TO REDUCE OXIDATIVE STRESS-RELATED EFFECTS ON THE OVARIES}

Although aging has historically been viewed as an inevitable and unstoppable process, it is entirely possible to slow down the aging rate. Owing to the important role of oxidative stress in ovarian aging, an enormous amount of related research has focused on antioxidants. Medicinal plants have been used for thousands of years and represent an extraordinary inventory of high-diversity 
structural scaffolds in addition to being the most important source of antioxidants (Xu DP et al., 2017). Moreover, antioxidants from medicinal plants seem to act on various diseases, including ovarian aging, with their excellent antioxidative stress capacities. Some natural compounds with antioxidant properties that are isolated from medicinal plants have also been shown to protect against ovarian aging through multiple mechanisms (Xu X et al., 2017). A summary of these findings and the main efficacy indicators and mechanisms are summarized in Table 1 and Figure 5.

\section{Resveratrol}

Resveratrol is a natural antioxidant polyphenol that is rich in the roots of Reynoutria japonica Houtt., wine, and grapes (Meng et al., 2020). Resveratrol has received extensive attention in recent years owing to its wide range of biological properties, including anti-aging, anti-oxidation, anti-inflammatory, and anti-cancer activities (Wang et al., 2018; Tong et al., 2020; Yu et al., 2020). Growing evidence indicates that resveratrol has potential effects in stimulating ovarian function and retarding ovarian aging. In POF animal models, induced by drugs, radiotherapy, or heavy metals, resveratrol significantly promotes primordial follicle activation, increases the number of primary, primordial, and growing follicles, stimulates GC proliferation, diminishes ovarian inflammation, maintains ovarian architecture, and rescues oocyte and GC apoptosis (Banu et al., 2016; Said et al., 2016; Liu Y et al., 2017; Chinwe et al., 2018; Li and Liu, 2018; Ata et al., 2019; Said et al., 2019; Wu et al., 2019; Ozatik et al., 2020). Besides these features, long-term (12 months) oral administration of resveratrol can prevent telomere shortening, increase telomerase activity to increase the primary and growing follicles, increase the oocyte quantity and quality, and enhance embryonic development in aging mice to achieve anti-ovarian aging (Liu et al., 2013). Treatment with resveratrol during in vitro maturation (IVM) has been shown to reverse the adverse effects of oxidative stress on oocytes, improve blastocyst production from oocytes, increase mtDNA copy numbers, and elevate ATP content in oocytes and subsequent embryo development ability as well as raise the rates of fertilization in postovulatory aging (POA) oocytes, maintain the normal morphology of spindle and mitochondrion distribution, and alleviate early apoptosis (Itami et al., 2015; Sugiyama et al., 2015; Piras et al., 2019; Sun et al., 2019; Ito et al., 2020). These studies suggest that resveratrol might serve as an effective approach to improve ovarian functions and delay ovarian aging, and its specific effects and mechanisms are as follows: 1) increases nuclear factor erythroid 2-related factor 2 (Nrf2), a redox-sensitive transcription factor that regulates the expression of antioxidant genes (Espinosa-Diez et al., 2015), total glutathione ( $\mathrm{tGSH}$ ), SOD, and SOD2; reduces ROS production and MDA levels; and reverses the adverse effects of oxidative stress; 2) promotes mitochondrial synthesis, increases transcription factor a (TFAM), polymerase subunit gamma (POLG), and peroxisome proliferator-activated receptor gamma coactivator 1- $\alpha$ (PGC1 $\alpha$ ) levels; 3 ) regulates the mitochondrial apoptotic pathway, reduces the release of Cyt $c$ and cleaved caspase- 3 , increases Bcl-2 and hypoxia-inducible factor 1-alpha (HIF1a), and inhibits oocytes and GC apoptosis; 4) acts as an anti-inflammation agent by inhibiting NF-kB-provoked inflammatory cytokines (IL-6, IL-8); 5) prevents telomere shortening and increases telomerase activity; and 6) regulates the expression of the SIRT1 gene while activating the PI3K/Akt signaling pathway.

\section{Quercetin}

Quercetin, a bioactive flavonoid, is widely found in medicinal plants and foods, such as Ginkgo biloba L., Hypericum perforatum L., apples, berries (Li Y et al., 2016). It has extensive biological properties, including antioxidant, anti-inflammatory, and antiapoptosis effects, and stimulates mitochondrial biogenesis ( $\mathrm{Li} \mathrm{Y}$ et al., 2016; Xu et al., 2019; Zeng et al., 2020). Recently, the use of quercetin in anti-ovarian aging treatment has been increasingly considered.

In laboratory animals, quercetin has been shown to increase the volume of the ovary and the primordial follicle number, the number of growing follicles along with the corpus luteum, and prevent follicular cell degeneration, hemorrhage, vascular congestion, and edema while decreasing apoptosis of follicular cells (Gencer et al., 2014; Nna et al., 2017; Bolouki et al., 2019; Elkady et al., 2019). In addition, in multiple in vitro studies using animal and human GCs, quercetin treatment enhanced viability of GCs, reduced the percentage of early apoptotic cells, relieved deterioration in oocyte quality, and improved subsequent embryo development (Wang $\mathrm{H}$ et al., 2017; Silva et al., 2018; Khadrawy et al., 2019; Rashidi et al., 2019). Accordingly, quercetin has a protective role in the ovaries,and its specific effects and mechanisms are as follows: 1) enhances Nrf2, SOD1, CAT, glutathione synthetase (GSS), $\mathrm{GSH}$, and glutathione peroxidase (GPx) activity; reduces ROS production and MDA levels; and inhibits oxidative stress; 2) decreases anti-apoptotic caspase levels; 3 ) inhibits the TLR/NF$\kappa \mathrm{B}$ inflammation signaling pathway; and 4) enhances mitochondrial activity.

\section{Curcumin}

Curcumin is the main natural polyphenol extracted from the rhizome of Curcuma longa L., which has been traditionally used in Asian countries as a medical herb for thousands of years (Kotha and Luthria, 2019). Curcumin is a widely studied nutraceutical and is known recently to have antioxidant, antiaging, anti-inflammatory, anti-apoptosis, and anti-cancer functions (Kocaadam and Şanlier, 2017; Bielak-Zmijewska et al., 2019; Boarescu et al., 2019). In laboratory animals, curcumin has been shown to play a stimulatory role in ovarian functions and prevents the compromise of ovarian functions caused by cyclophosphamide (CPM), ionizing radiation, and ischemia (Alekseyeva et al., 2011; Aktas et al., 2012; Sak et al., 2013; Qin et al., 2015; Wang XN et al., 2017; Mohammadi et al., 2017; Melekoglu et al., 2018; Yan et al., 2018). Treatment with curcumin has been shown to increase the number of follicles at different developmental stages and in GCs, improve histological appearance of oocytes, and markedly reduce atretic follicles, lipid peroxidation, hemorrhage around the corpus luteum, and vascular congestion in the ovarian stroma 
TABLE 1 | Efficacy of natural antioxidants in protecting against ovarian aging.

\section{Active} ingredients

Resveratrol

Proanthocyanidin

Crocetin

Mogroside V

Experimental model

Efficacy

References

MTX-induced ovarian-damaged rats Cisplatin-induced ovarian-damaged rats Radiotherapy-induced POF rats Busulfan/cyclophosphamide-induced ovarianaging mice

Rats exposed to chromium

VCD-induced diminished ovarian follicle rats

Mice exposed to Mancozeb

C57/BL6 female mice under long-term oral administration of resveratrol

Aging oocytes of mice

Aged bovine oocytes and GCs

Vitrified-warmed porcine oocytes CP-induced POF mice

\section{Streptozotocin-induced diabetic mice}

Experimental ovarian ischemia-reperfusion injury rats

Cadmium chloride-induced reproductive toxicity rats

Goat oocytes

$\mathrm{H}_{2} \mathrm{O}_{2}$-induced oxidatively stressed human GCs

$\mathrm{H}_{2} \mathrm{O}_{2}$-induced oxidatively stressed bovine GCs

Oocytes of aging mice

D-galactose-induced POF model mice

Sodium arsenite-induced ovarian oxidative injury mice

Exposed-to-whole-body ionizing radiation mice

Zearalenone-induced oxidative stress

porcine GCs

Estradiol valerate-induced PCOS rats

CPM-induced POF rats

Rat ovaries with ischemia-reperfusion injury

D-gal-induced aging hens

3-NPA-induced ovarian oxidatively damaged mice

Human GCs

Diquat-induced ovarian oxidatively damaged mice

Mice oocytes

Mouse oocytes

CPM-induced ovary injury mice

Porcine oocytes

Porcine oocytes
Counteracts MTX-induced cytotoxicity in rat ovary

Prevents the loss of the GCs

Restores ovarian function and diminishes ovarian inflammation

Improves ovarian aging and renewal capacity of oogonial stem cell

Mitigates chromium-induced follicle atresia; rescues oocytes and GCs from apoptosis

Improves VCD-induced DOR; increases the number of primary, primordial, and growing follicles

Alleviates Mancozeb induced infertility; increases ovary weight and primary follicles

Increases primary and growing follicles; enhances oocyte quantity and quality in aged mice; counteracts age-related fertility decline

Increases the rates of fertilization and blastocyst in POA oocytes; reduces the loss of sperm-binding sites; maintains the normal morphology of spindle and mitochondrion distribution; alleviates early apoptosis Improves the developmental progress of oocytes to the blastocyst stage; increases the mtDNA copy numbers and ATP content of oocytes Improves survival, maturation, and MMP of vitrified-warmed oocytes Increases primordial follicles number and $\mathrm{AMH}$ level; decreases atretic follicles number

Increases the volume of the ovaries and growing follicles, significantly decreases the number of atretic follicles

Prevents follicular cell degeneration, hemorrhage, vascular congestion, and edema

Increases the number of follicles; decreases apoptosis of follicular cells

Improves mitochondrial activity and the percentage of MII oocytes;

decreases the rate of apoptosis of MII oocytes

Significantly improves viability of human GCs; reduces the percentage of early apoptotic cells

Increases GC proliferation and mitochondrial activity; reduces intracellular ROS levels

Relieves deterioration in oocyte quality and improves subsequent embryo development

Increases the follicles at different developmental stages

Markedly reduces atretic follicles; increases the number of GCs

Improves histological appearance of oocytes; reduces follicular atresia and GC apoptosis

Rescues oxidative stress induced by Zearalenone

Significantly increases the number of primordial follicles, preantral, and corpus luteum; reduces the number of cysts and antral follicles

Significantly reduces atretic follicle, lipid peroxidation, hemorrhage around the corpus luteum, and vascular congestion in the ovarian stroma;

improves histological parameters

Reverses tissue damage induced by ischemia-reperfusion injury in ovarian torsion

Decreases the oxidative stress, alleviates the inhibition of aging on ovarian somatic cell proliferation, and decreases cell apoptosis

Significantly lower the percentage of GCs apoptosis and atretic follicles

Decreases oxidative stress and increases steroidogenesis Improves GCs viability, reduces GCs apoptosis rate, and induces autophagy process

Improves IVM outcomes

Improves nuclear maturation rates and subsequent developmental potential of mouse oocytes

Reduces follicle loss; rescues fertility in CPM-treated mice Improves IVM outcomes and subsequent embryonic development Protects porcine oocytes against in vitro aging
Ata et al. (2019)

Said et al. (2019)

Said et al. (2016)

Wu et al. (2019)

Banu et al. (2016)

Ozatik et al. (2020)

Liu Y et al. (2017)

Liu et al. (2013)

Sun et al. (2019)

Sugiyama et al. (2015)

Ito et al. (2020)

Elkady et al. (2019)

Bolouki et al. (2019)

Gencer et al. (2014)

Nna et al. (2017)

Silva et al. (2018)

Rashidi et al. (2019)

Khadrawy et al. (2019)

Wang $\mathrm{H}$ et al. (2017)

Yan et al. (2018)

Wang XN et al. (2017)

Aktas et al. (2012)

Qin et al. (2015)

Mohammadi et al. (2017)

Melekoglu et al.

(2018)

Sak et al. (2013)

Liu X et al. (2018)

Qin et al. (2015)

Barbe et al. (2019)

Zhang et al. (2016)

Mokhber Maleki et al. (2014)

Mokhber Maleki et al. (2014)

Di Emidio et al. (2017)

Nie et al. (2020)

Nie et al. (2019)

(Continued on following page) 
TABLE 1 | (Continued) Efficacy of natural antioxidants in protecting against ovarian aging.

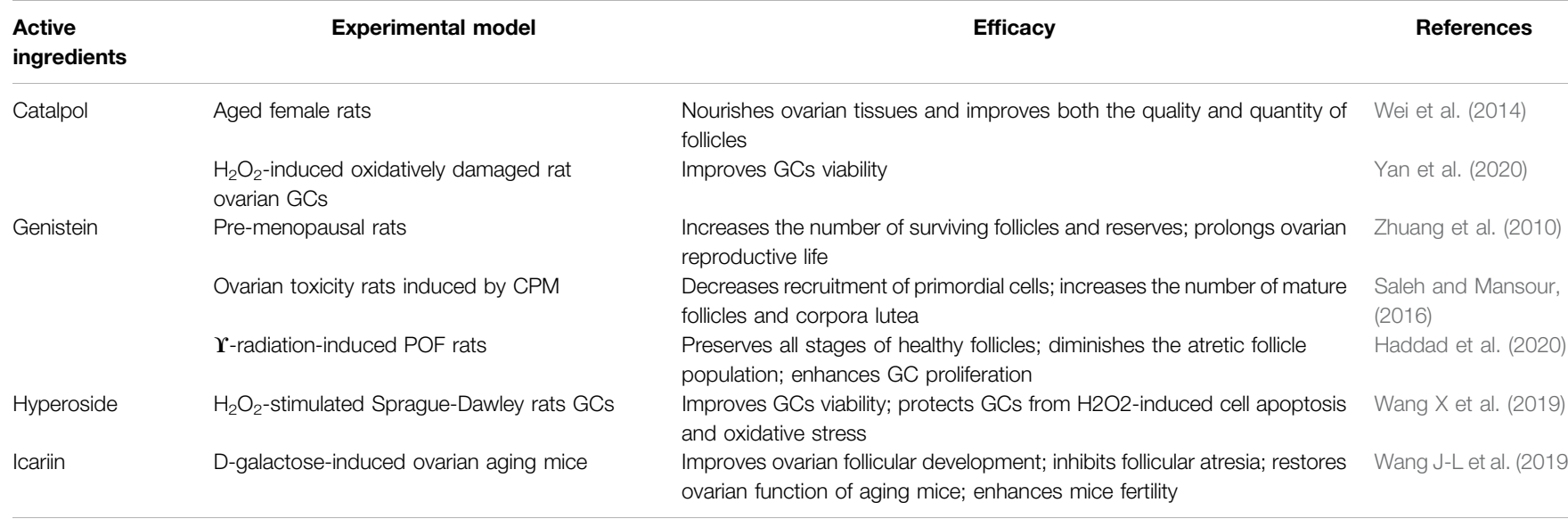

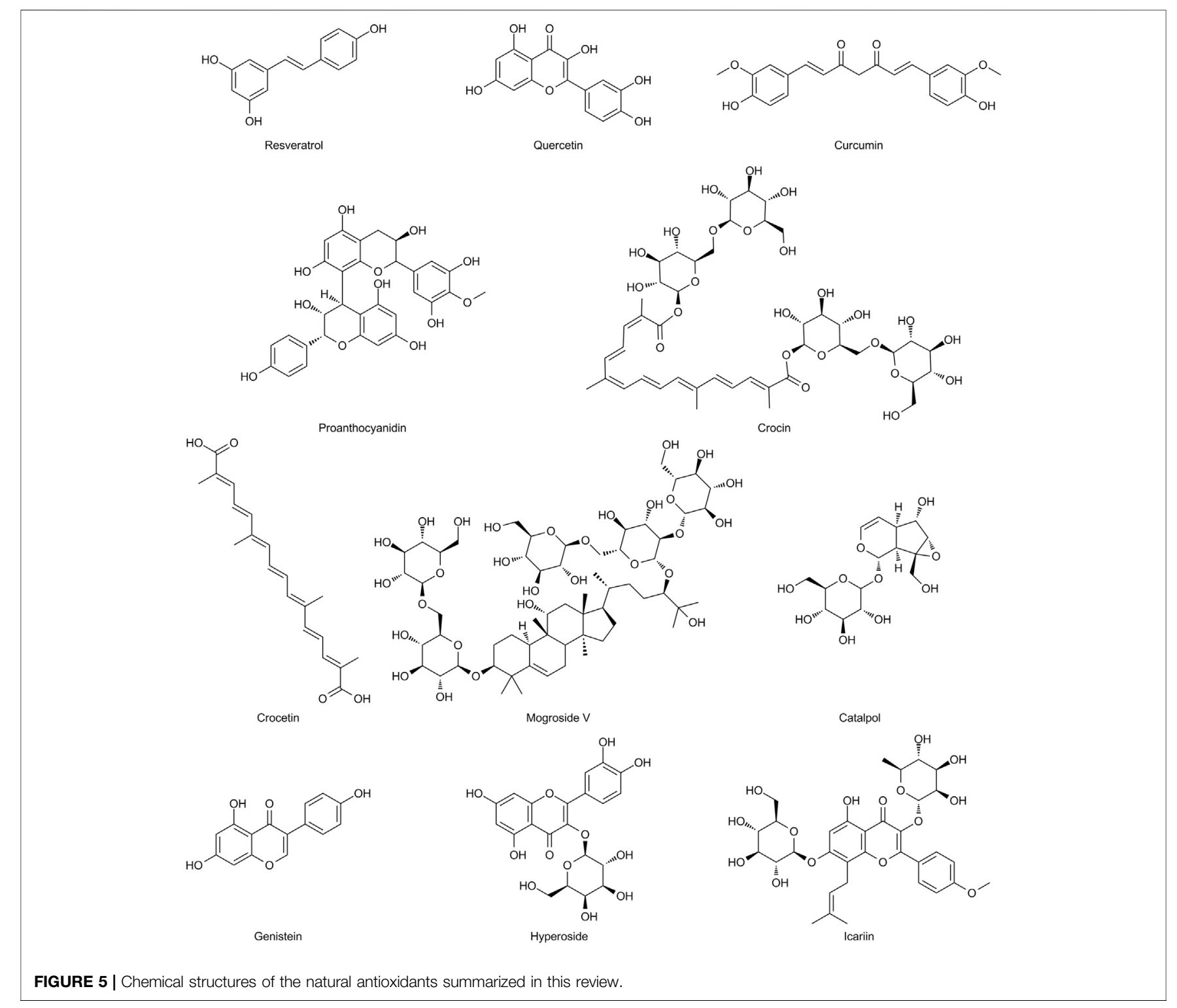




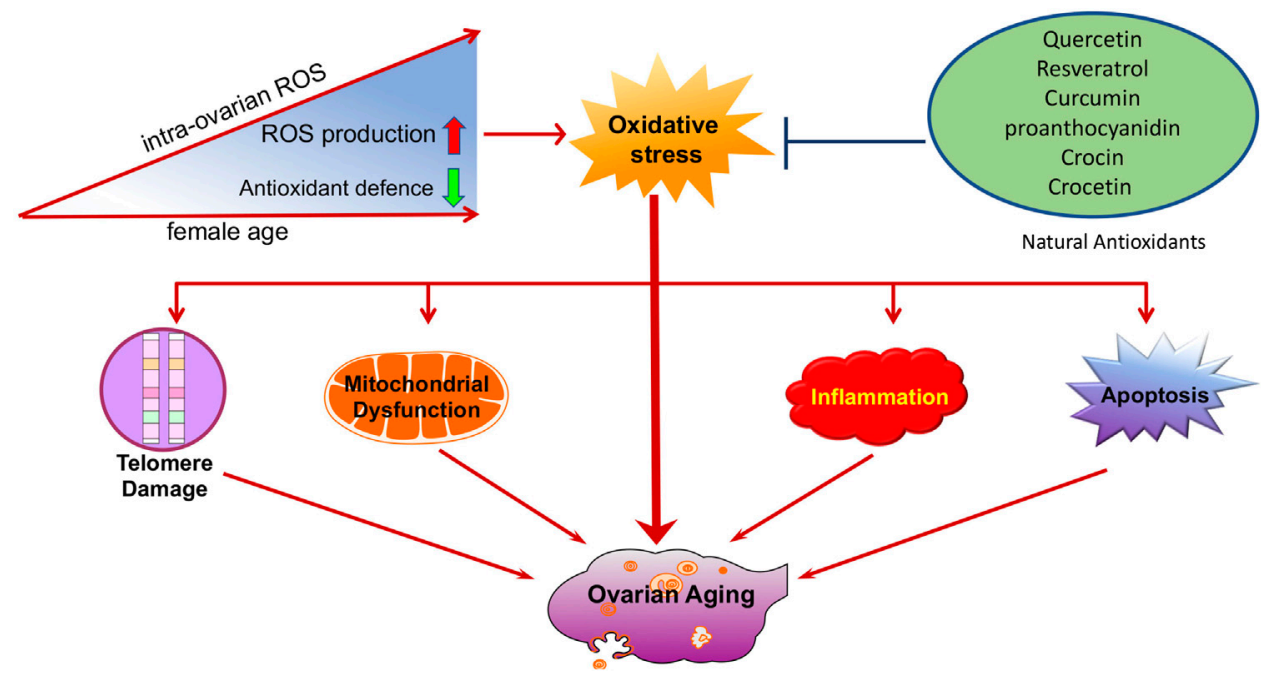

FIGURE 6 | Schematic illustration of oxidative stress during ovarian aging. Oxidative stress promotes the development of other ovarian aging-related etiologies, including telomere shortening, mitochondrial dysfunction, apoptosis, and inflammation. Natural antioxidants supplements, such as resveratrol, quercetin, and curcumin might be beneficial in preventing ovarian aging.

(Alekseyeva et al., 2011; Aktas et al., 2012; Sak et al., 2013; Qin et al., 2015; Wang XN et al., 2017; Mohammadi et al., 2017; Melekoglu et al., 2018; Yan et al., 2018). The specific effects and mechanisms involved are as follows: 1) alleviates ovarian oxidative injury, increases the levels of Nrf2, heme oxygenase1(HO-1), SOD, and SOD1 while reducing ROS production and MDA levels; 2) decreases anti-apoptotic levels of caspase-3 and -9; and 3) as an anti-inflammation agent, reduces the levels of TNF- $\alpha$, IL-6, and CRP.

\section{Proanthocyanidin}

Proanthocyanidin (PA) is an important class of polyphenols abundant in grape seeds, Lycium ruthenicum Murry., and blueberries, possessing antioxidant, anti-inflammatory, and anticancer activities (Shi et al., 2003; He et al., 2018). In hens, PA treatment significantly alleviated the inhibition of ovarian somatic cell proliferation and decreased cell apoptosis in D-gal-induced and natural aging ovarian tissues by reducing oxidative stress (Liu X et al., 2018). Similarly, in 3-nitropropionic acid (3-NPA)-induced oxidative ovarian damaged mice, PA significantly reduced the percentage of GC apoptosis and atretic follicles in ovarian tissues, increased the expression of antioxidant genes, and inhibited the expression of proapoptotic genes (Zhang JQ et al., 2015). In addition, in multiple in vitro studies using animal and human GCs, PA and procyanidin B2 (B type of PA) exert a potent effect in terms of diminishing GC apoptosis and intracellular ROS production (Zhang et al., 2016; Barbe et al., 2019). Taken together, the administration of PA has the potential to alleviate ovarian oxidative injury and delay ovarian aging mainly through antioxidant and anti-apoptotic activities.

\section{Crocin and Crocetin}

Crocin and crocetin are both carotenoid chemical compounds of Crocus sativus L. and are well-known in traditional medicine (Leone et al., 2018). They show high radical-scavenging activity as well as anti-inflammatory, anti-apoptosis, and probably anti-aging activity (Assimopoulou et al., 2005; Bukhari et al., 2018). Abedi et al. demonstrated that supplementation of IVM media with crocin significantly reduces the adverse effects of oxidative stress, thereby improving nuclear maturation rates and subsequent developmental potential of mouse oocytes (Mokhber Maleki et al., 2014; Mokhber Maleki et al., 2016). In addition, crocetin administration reduces follicle loss and rescues fertility in CPM-treated mice. Mechanistically, crocetin protects the ovary against CPM by modulating redox balance, decreasing SIRT3, and increasing the antioxidant enzyme, SOD2, as well as the mitochondrial biogenesis activator, PGC1a (Di Emidio et al., 2017).

\section{Mogroside V}

Mogroside V (MV) is the most abundant form of triterpenoid compound isolated from Siraitia grosvenorii (Swingle) C.Jeffrey ex A.M.Lu \& Zhi Y.Zhang (Liu H et al., 2018; Gong et al., 2019). Numerous studies have demonstrated that MV possesses broad pharmacological characteristics and properties, including antioxidant, anti-tussive, immunoregulatory, and antiinflammatory effects (Di et al., 2011; Itkin et al., 2016; Liu C et al., 2018). Liang et al. reported that supplementation of IVM media with MV significantly increased the IVM rate and subsequent embryonic development. Furthermore, MV reduced intracellular ROS and increased the mRNA expression of oxidative stress-related genes (SOD, CAT, and SIRT1) while enhancing mitochondrial function (Nie et al., 2020). MV markedly reduces the decline in porcine oocyte quality during in vitro aging, possibly by reducing oxidative stress and early apoptosis in aged oocytes while improving mitochondrial contents and function (Nie et al., 2019).

\section{Catalpol}

Catalpol is an iridoid glycoside abundant in the roots of Rehmannia glutinosa (Gaertn.) DC. and has been shown to 


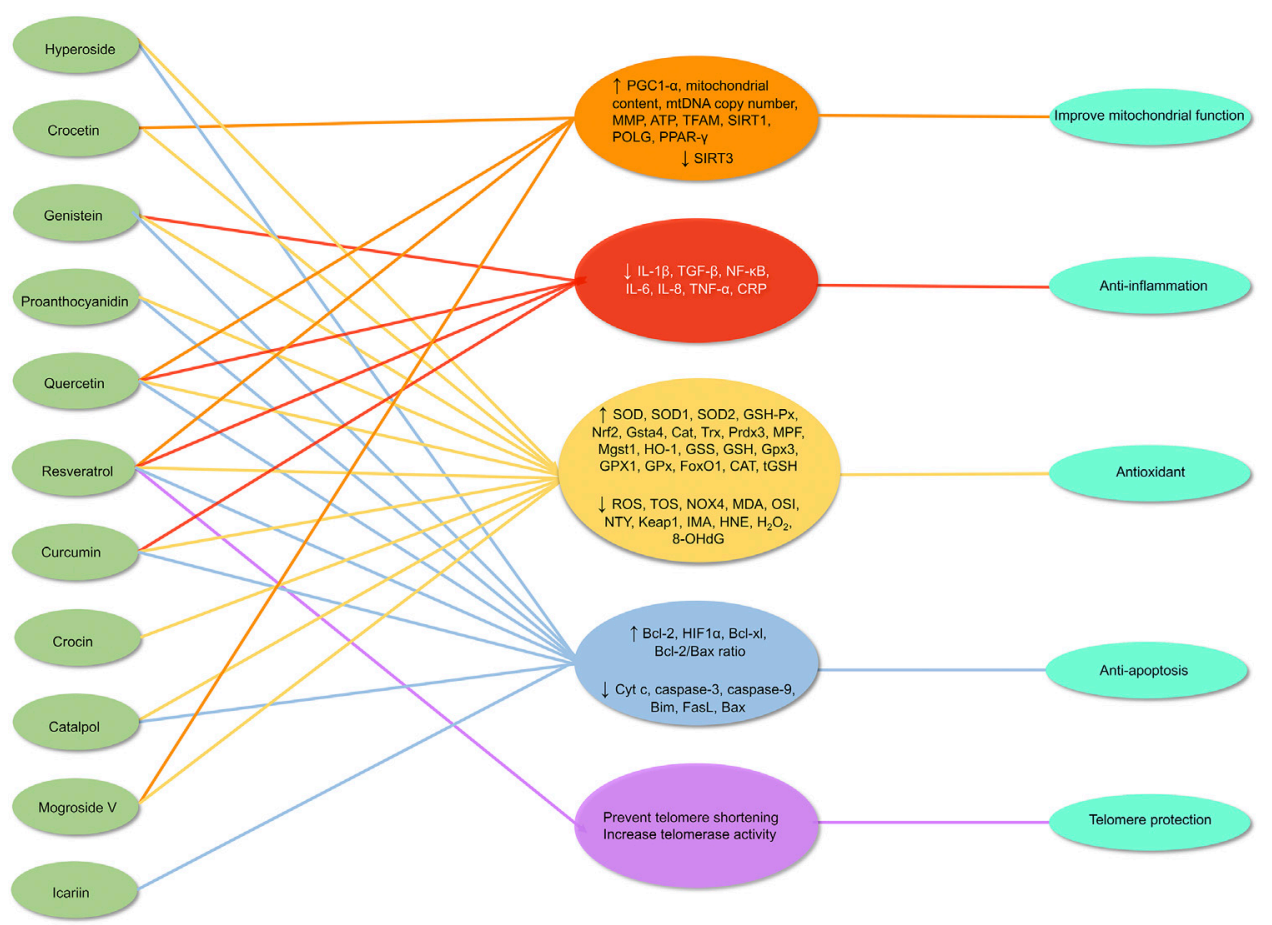

FIGURE 7 | Mechanism of natural antioxidants in protecting against ovarian aging through multiple mechanisms. $\uparrow=$ up-regulates, $\downarrow=$ down-regulates.

possess a broad range of bioactivities, especially antioxidative effects, and is considered a potential candidate for treating oxidative stress-induced neurodegenerative disease (Jiang et al., 2015; Tong et al., 2015; Zheng et al., 2017). Recently, the protective role of catalpol in the ovaries has also been confirmed. Studies have shown that catalpol can nourish ovarian tissue and improve the quality and quantity of follicles and has a direct anti-aging effect on the rat ovarian system (Wei et al., 2014). Catalpol also improved GC viability and protected GCs from $\mathrm{H}_{2} \mathrm{O}_{2}$-induced oxidative injury and apoptosis (Yan et al., 2020). The mechanism likely involved is that catalpol inhibits $\mathrm{H}_{2} \mathrm{O}_{2}$-induced ROS, MDA, Bax, and caspase-9 production while activating SOD, GSH-Px, and Bcl-2 expression (Yan et al., 2020).

\section{Genistein}

Genistein, one of the most important isoflavones, is found in soybean products, and in the traditional medicinal plants, including Pueraria montana (Lour.) Merr., Cistanche deserticola Ma, and Eucommia ulmoides Oliv. (Park et al., 2019; Tang et al., 2019). It shows estrogenic properties via binding to different estrogen receptors and has various biological effects in antioxidation and anti-aging (Spagnuolo et al., 2015; Liu et al., 2020). Indeed, in vitro studies have shown that genistein increased the number of follicles surviving as reserves and prolonged ovarian reproductive life (Zhuang et al., 2010). In addition, genistein alleviated the oxidative stress and inflammation in CMP-induced ovarian toxicity rats (Saleh and Mansour, 2016). Specifically, genistein decreased the recruitment of primordial cells and increased the number of mature follicles and corpora lutea by upregulating ovarian SOD and GSH levels, and downregulating IL- $1 \beta$ and MAD levels, which means preservation of ovarian function and follicular reservoirs (Saleh and Mansour, 2016). Moreover, compared with estradiol, genistein was superior in preserving all stages of healthy follicles, enhancing GCs proliferation, and reducing the population of atretic follicles in $\mathbf{\Upsilon}$-radiation-induced POF rats (Haddad et al., 2020).

There are several other natural compounds with antioxidant, anti-inflammatory, anti-apoptosis, and antiaging properties, such as hyperoside and icariin, which may also exert beneficial effects on ovarian aging (Wang J-L et al., 2019; Wang X et al., 2019). The chemical structures of the natural antioxidants summarized in this review are presented in Figure 6.

Apart from natural compounds, various diets rich in antioxidants are also sources of natural antioxidants. For example, kiwifruit, nuts, tomatoes are rich in vitamins $\mathrm{C}, \mathrm{D}$, and $\mathrm{E}$; walnuts, peanuts, cherries, corn are high in melatonin. A prospective study showed that there is a highly significant correlation between vitamin D deficiency and DOR (Arefi et al., 2018). The combined use of vitamin $\mathrm{E}$ and $\mathrm{C}$ can prevent apoptosis of ovarian tissue following mancozeb exposure in the first generation of mouse pups (Mahdi et al., 2019). In addition, melatonin may act as a free radical scavenger and has antioxidant properties. Its role in anti-ovarian aging has been widely reported. Oral melatonin can ameliorate intrafollicular oxidative stress, improve the quantity and 
quality of oocytes and IVF outcomes (Jahromi et al., 2017; Espino et al., 2019; Hu et al., 2020). In contrast, night shift work may lead to impaired pineal function and inhibit melatonin production (James et al., 2017). Teixeira et al. reported that night shift workers have a higher level of oxidative stress damage and a lower level of antioxidant defenses (Teixeira et al., 2019). Women who rotate night shift work have an increased risk of early menopause and ovarian failure (Stock et al., 2019). Therefore, healthy sleep also contributes to antioxidant stress and antiovarian aging.

\section{CONCLUSION}

Driven by societal trends, many young women choose to postpone marriage and/or childbirth. Age-related fertility issues have become serious challenges in reproductive medicine because aging causes a reduction in both oocyte quality and quantity. Oxidative stress is a crucial factor in ovarian functional decline with age. It acts as a driver of the etiology of ovarian aging. Compelling evidence has shown that oxidative stress promotes the development of other ovarian aging-related etiologies, including telomere shortening, mitochondrial dysfunction, apoptosis, and inflammation, which provides new insights into our understanding of the mechanisms of ovarian aging.

Therefore, alleviating oxidative stress in the ovaries is an important entry point for delaying ovarian aging. Compared with synthetic antioxidants, antioxidants from natural products have a high anti-oxidative stress capacity and are safe and acceptable. In our review, certain natural antioxidants have

\section{REFERENCES}

Abais, J. M., Xia, M., Zhang, Y., Boini, K. M., and Li, P. L. (2015). Redox regulation of NLRP3 inflammasomes: ROS as trigger or effector?. Antioxid Redox Signal. 22 (13), 1111-1129. doi:10.1089/ars.2014.5994

Agharazii, M., St-Louis, R., Gautier-Bastien, A., Ung, R.-V., Mokas, S., Larivière, R., et al. (2014). Inflammatory cytokines and reactive oxygen species as mediators of chronic kidney disease-related vascular calcification. Am. J. Hypertens. 28 (6), 746-755. doi:10.1093/ajh/hpu225

Aktas, C., Kanter, M., and Kocak, Z. (2012). Antiapoptotic and proliferative activity of curcumin on ovarian follicles in mice exposed to whole body ionizing radiation. Toxicol. Ind. Health. 28 (9), 852-863. doi:10.1177/ 0748233711425080

Alekseyeva, I. N., Makogon, N. V., Bryzgina, T. M., Voznesenskaya, T. Y., and Sukhina, V. S. (2011). Effects of NF- $\kappa B$ blocker curcumin on oogenesis and immunocompetent organ cells in immune ovarian injury in mice. Bull. Exp. Biol. Med. 151 (4), 432-435. doi:10.1007/s10517-011-1349-1

Amanvermez, R., and Tosun, M. (2016). An update on ovarian aging and ovarian reserve tests. Int. J. Fertil. Steril. 9 (4), 411-415. doi:10.22074/ijfs. 2015.4591

Arcos, A., de Paola, M., Gianetti, D., Acuña, D., Velásquez, Z. D., Miró, M. P., et al. (2017). $\alpha$-SNAP is expressed in mouse ovarian granulosa cells and plays a key role in folliculogenesis and female fertility. Sci. Rep. 7 (1), 11765. doi:10.1038/ s41598-017-12292-9

Arefi, S., Khalili, G., Iranmanesh, H., Farifteh, F., Hosseini, A., Fatemi, H. M., et al. (2018). Is the ovarian reserve influenced by vitamin D deficiency and the dress code in an infertile Iranian population?. J. Ovarian Res. 11 (1), 62. doi:10.1186/ s13048-018-0435-7 been tested in vivo and in vitro with promising results and multiple mechanisms. These findings raise the prospect of oxidative stress modulatory natural antioxidants as therapeutic interventions for delaying ovarian aging (Figure 7). While substantial research supports these strategies, further investigation is warranted, particularly through clinical trials.

\section{AUTHOR CONTRIBUTIONS}

QZ conceptualized the manuscript. LY, XC, YC, YL, LY, YX, CM, and $\mathrm{YZ}$ collected the literature, wrote the manuscript, and prepared figures. QZ edited and made significant revisions to the manuscript. All authors contributed to the article and approved the submitted version.

\section{FUNDING}

QZ got the Programs: Zhejiang Provincial TCM Sci-tech Plan (2020ZA078) and Zhejiang Zhangqin famous Traditional Chinese Medicine expert inheritance studio project (GZS2012014). YC got the Program: Medical and health science and technology plan of Zhejiang Province (2021KY920).

\section{ACKNOWLEDGMENTS}

We would like to thank Editage (http://www.editage.cn) for English language editing of the manuscript.

Arulselvan, P., Fard, M. T., Tan, W. S., Gothai, S., Fakurazi, S., Norhaizan, M. E., et al. (2016). Role of antioxidants and natural products in inflammation. Oxid. Med. Cell Longev. 2016, 5276130. doi:10.1155/2016/5276130

Aryaman, J., Hoitzing, H., Burgstaller, J. P., Johnston, I. G., and Jones, N. S. (2017). Mitochondrial heterogeneity, metabolic scaling and cell death. Bioessays. 39 (7) doi:10.1002/bies.201700001

Assimopoulou, A. N., Sinakos, Z., and Papageorgiou, V. P. (2005). Radical scavenging activity of Crocus sativus $\mathrm{L}$. extract and its bioactive constituents. Phytother Res. 19 (11), 997-1000. doi:10.1002/ptr.1749

Ata, N., Kulhan, N. G., Kulhan, M., Turkler, C., Kiremitli, T., Kiremitli, S., et al. (2019). The effect of resveratrol on oxidative ovary-damage induced by methotrexate in rats (Resveratrol oxidative ovary-damage). Gen. Physiol. Biophys. 38 (6), 519-524. doi:10.4149/gpb_20190281

Banu, S. K., Stanley, J. A., Sivakumar, K. K., Arosh, J. A., and Burghardt, R. C. (2016). Resveratrol protects the ovary against chromium-toxicity by enhancing endogenous antioxidant enzymes and inhibiting metabolic clearance of estradiol. Toxicol. Appl. Pharmacol. 303, 65-78. doi:10.1016/j.taap.2016.04.016

Barbe, A., Ramé, C., Mellouk, N., Estienne, A., Bongrani, A., Brossaud, A., et al. (2019). Effects of grape seed extract and proanthocyanidin B2 on in vitro proliferation, viability, steroidogenesis, oxidative stress, and cell signaling in human granulosa cells. Int. J. Mol. Sci. 20 (17), 4215. doi:10.3390/ijms20174215

Bauer, D., Werth, F., Nguyen, H. A., Kiecker, F., and Eberle, J. (2017). Critical role of reactive oxygen species (ROS) for synergistic enhancement of apoptosis by vemurafenib and the potassium channel inhibitor TRAM-34 in melanoma cells. Cell Death Dis. 8 (2), e2594. doi:10.1038/cddis.2017.6

Bellantuono, I. (2018). Find drugs that delay many diseases of old age. Nature 554 (7692), 293-295. doi:10.1038/d41586-018-01668-0

Bertone-Johnson, E. R., Manson, J. E., Purdue-Smithe, A. C., Hankinson, S. E., Rosner, B. A., and Whitcomb, B. W. (2019). A prospective study of 
inflammatory biomarker levels and risk of early menopause. Menopause 26 (1), 32-38. doi:10.1097/gme.0000000000001162

Bielak-Zmijewska, A., Grabowska, W., Ciolko, A., Bojko, A., Mosieniak, G., Bijoch, Ł., et al. (2019). The role of curcumin in the modulation of ageing. Int. J. Mol. Sci. 20 (5), 1239. doi:10.3390/ijms20051239

Biswas, S. K. (2016). Does the interdependence between oxidative stress and inflammation explain the antioxidant paradox? Oxid. Med. Cell Longev. 2016, 5698931. doi:10.1155/2016/5698931

Boarescu, P. M., Boarescu, I., Boarescu, I. C., Gheban, D., Bulboacă, A. E., Nicula, C., et al. (2019). Antioxidant and anti-inflammatory effects of curcumin nanoparticles on drug-induced acute myocardial infarction in diabetic rats. Antioxidants 8 (10), 504. doi:10.3390/antiox8100504

Bolouki, A., Zal, F., and Bordbar, H. (2019). Ameliorative effects of quercetin on folliculogenesis in diabetic mice: a stereological study. Gynecol. Endocrinol. 36, 864-868. doi:10.1080/09513590.2019.1707796

Bukhari, S. I., Manzoor, M., and Dhar, M. K. (2018). A comprehensive review of the pharmacological potential of Crocus sativus and its bioactive apocarotenoids. Biomed. Pharmacother. 98, 733-745. doi:10.1016/j.biopha.2017.12.090

Butterfield, D. A., and Boyd-Kimball, D. (2018). Oxidative stress, amyloid- $\beta$ peptide, and altered key molecular pathways in the pathogenesis and progression of alzheimer's disease. J. Alzheimers Dis. 62 (3), 1345-1367. doi:10.3233/jad-170543

Butts, S., Riethman, H., Ratcliffe, S., Shaunik, A., Coutifaris, C., and Barnhart, K. (2009). Correlation of telomere length and telomerase activity with occult ovarian insufficiency. J. Clin. Endocrinol. Metab. 94 (12), 4835-4843. doi:10. 1210/jc.2008-2269

Cajas, Y. N., Cañón-Beltrán, K., Ladrón de Guevara, M., Millán de la Blanca, M. G., Ramos-Ibeas, P., Gutiérrez-Adán, A., et al. (2020). Antioxidant nobiletin enhances oocyte maturation and subsequent embryo development and quality. Int. J. Mol. Sci. 21 (15), 5340. doi:10.3390/ijms21155340

Caston, R. A., and Demple, B. (2017). Risky repair: DNA-protein crosslinks formed by mitochondrial base excision DNA repair enzymes acting on free radical lesions. Free Radic. Biol. Med. 107, 146-150. doi:10.1016/j.freeradbiomed.2016. 11.025

Cecchino, G. N., and Garcia-Velasco, J. A. (2019). Mitochondrial DNA copy number as a predictor of embryo viability. Fertil. Steril. 111 (2), 205-211. doi:10. 1016/j.fertnstert.2018.11.021

Chaube, S. K., Shrivastav, T. G., Tiwari, M., Prasad, S., Tripathi, A., and Pandey, A. K. (2014). Neem (Azadirachta indica L.) leaf extract deteriorates oocyte quality by inducing ROS-mediated apoptosis in mammals. Springerplus. 3, 464. doi:10. 1186/2193-1801-3-464

Cheng, E. H., Chen, S. U., Lee, T. H., Pai, Y. P., Huang, L. S., Huang, C. C., et al. (2013). Evaluation of telomere length in cumulus cells as a potential biomarker of oocyte and embryo quality. Hum. Reprod. 28 (4), 929-936. doi:10.1093/ humrep/det004

Chinwe, G. S., Azuka, O. I., and Adaeze, N. C. (2018). Resveratrol supplementation rescues pool of growing follicles and ovarian stroma from Cisplatin-induced toxicity on the ovary in Sprague-Dawley rats: an experimental study. Int. J. Reprod. Biomed. 16 (1), 19-30. doi:10.29252/ijrm.16.1.19

Chung, H. Y., Kim, D. H., Lee, E. K., Chung, K. W., Chung, S., Lee, B., et al. (2019). Redefining chronic inflammation in aging and age-related diseases: proposal of the senoinflammation concept. Aging Dis. 10 (2), 367-382. doi:10.14336/ad. 2018.0324

Cioffi, F., Adam, R. H. I., and Broersen, K. (2019). Molecular mechanisms and genetics of oxidative stress in alzheimer's disease. J. Alzheimers Dis. 72 (4), 981-1017. doi:10.3233/jad-190863

Circu, M. L., and Aw, T. Y. (2010). Reactive oxygen species, cellular redox systems, and apoptosis. Free Radic. Biol. Med. 48 (6), 749-762. doi:10.1016/j. freeradbiomed.2009.12.022

Coluzzi, E., Leone, S., and Sgura, A. (2019). Oxidative stress induces telomere dysfunction and senescence by replication fork arrest. Cells 8 (1), 19. doi:10. 3390/cells8010019

Conca Dioguardi, C., Uslu, B., Haynes, M., Kurus, M., Gul, M., Miao, D. Q., et al. (2016). Granulosa cell and oocyte mitochondrial abnormalities in a mouse model of fragile X primary ovarian insufficiency. Mol. Hum. Reprod. 22 (6), 384-396. doi:10.1093/molehr/gaw023

Corn, C. M., Hauser-Kronberger, C., Moser, M., Tews, G., and Ebner, T. (2005). Predictive value of cumulus cell apoptosis with regard to blastocyst development of corresponding gametes. Fertil. Steril. 84 (3), 627-633. doi:10.1016/j.fertnstert.2005.03.061

Cui, L. L., Yang, G., Pan, J., and Zhang, C. (2011). Tumor necrosis factor a knockout increases fertility of mice. Theriogenology 75 (5), 867-876. doi:10. 1016/j.theriogenology.2010.10.029

de Kat, A. C., Verschuren, W. M., Eijkemans, M. J., van der Schouw, Y. T., and Broekmans, F. J. (2016). The association of low ovarian reserve with cardiovascular disease risk: a cross-sectional population-based study. Hum. Reprod. 31 (8), 1866-1874. doi:10.1093/humrep/dew159

Dechanet, C., Anahory, T., Mathieu Daude, J. C., Quantin, X., Reyftmann, L., Hamamah, S., et al. (2011). Effects of cigarette smoking on reproduction. Hum. Reprod. Update 17 (1), 76-95. doi:10.1093/humupd/dmq033

Di Emidio, G., Rossi, G., Bonomo, I., Alonso, G. L., Sferra, R., Vetuschi, A., et al. (2017). The natural carotenoid crocetin and the synthetic tellurium compound AS101 protect the ovary against cyclophosphamide by modulating SIRT1 and mitochondrial markers. Oxid. Med. Cell Longev. 2017, 1-14. doi:10.1155/2017/ 8928604

Di, R., Huang, M. T., and Ho, C. T. (2011). Anti-inflammatory activities of mogrosides from Momordica grosvenori in murine macrophages and a murine ear edema model. J. Agric. Food Chem. 59 (13), 7474-7481. doi:10. $1021 / \mathrm{jf} 201207 \mathrm{~m}$

Dizdaroglu, M., and Jaruga, P. (2012). Mechanisms of free radical-induced damage to DNA. Free Radic. Res. 46 (4), 382-419. doi:10.3109/10715762.2011.653969

Domènech, E. B., and Marfany, G. (2020). The relevance of oxidative stress in the pathogenesis and therapy of retinal dystrophies. Antioxidants 9 (4), 347. doi:10. 3390/antiox 9040347

Edrey, Y. H., and Salmon, A. B. (2014). Revisiting an age-old question regarding oxidative stress. Free Radic. Biol. Med. 71, 368-378. doi:10.1016/j. freeradbiomed.2014.03.038

Elkady, M. A., Shalaby, S., Fathi, F., and El-Mandouh, S. (2019). Effects of quercetin and rosuvastatin each alone or in combination on cyclophosphamide-induced premature ovarian failure in female albino mice. Hum. Exp. Toxicol. 38 (11), 1283-1295. doi:10.1177/0960327119865588

Erusalimsky, J. D. (2020). Oxidative stress, telomeres and cellular senescence: what non-drug interventions might break the link? Free Radic. Biol. Med. 150, 87-95. doi:10.1016/j.freeradbiomed.2020.02.008

Espino, J., Macedo, M., Lozano, G., Ortiz, Á., Rodríguez, C., Rodríguez, A. B., et al. (2019). Impact of melatonin supplementation in women with unexplained infertility undergoing fertility treatment. Antioxidants 8 (9), 338. doi:10.3390/ antiox 8090338

Espinosa-Diez, C., Miguel, V., Mennerich, D., Kietzmann, T., Sánchez-Pérez, P., Cadenas, S., et al. (2015). Antioxidant responses and cellular adjustments to oxidative stress. Redox Biol. 6, 183-197. doi:10.1016/j.redox.2015.07.008

Fan, Y., Chang, Y., Wei, L., Chen, J., Li, J., Goldsmith, S., et al. (2019). Apoptosis of mural granulosa cells is increased in women with diminished ovarian reserve. J. Assist. Reprod. Genet. 36 (6), 1225-1235. doi:10.1007/s10815-019-01446-5

Franceschi, C., Garagnani, P., Morsiani, C., Conte, M., Santoro, A., Grignolio, A., et al. (2018a). The continuum of aging and age-related diseases: common mechanisms but different rates. Front. Med. 5, 61. doi:10.3389/fmed.2018.00061

Franceschi, C., Garagnani, P., Parini, P., Giuliani, C., and Santoro, A. (2018b). Inflammaging: a new immune-metabolic viewpoint for age-related diseases. Nat. Rev. Endocrinol. 14 (10), 576-590. doi:10.1038/s41574-018-0059-4

Gencer, M., Karaca, T., Gungor, A., Hacıvelioğlu, S., demirtaș, S., Türkön, H., et al. (2014). The protective effect of quercetin on IMA levels and apoptosis in experimental ovarian ischemia-reperfusion injury. Eur. J. Obstet. Gynecol. Reprod. Biol. 177, 135-140. doi:10.1016/j.ejogrb.2014.03.036

Gong, X., Chen, N., Ren, K., Jia, J., Wei, K., Zhang, L., et al. (2019). The fruits of Siraitia grosvenorii: a review of a Chinese food-medicine. Front. Pharmacol. 10, 1400. doi:10.3389/fphar.2019.01400

Guicciardi, M. E., and Gores, G. J. (2009). Life and death by death receptors. Faseb. J. 23 (6), 1625-1637. doi:10.1096/fj.08-111005

Haddad, Y. H., Said, R. S., Kamel, R., Morsy, E. M. E., and El-Demerdash, E. (2020). Phytoestrogen genistein hinders ovarian oxidative damage and apoptotic cell death-induced by ionizing radiation: co-operative role of ER- $\beta$, TGF- $\beta$, and FOXL-2. Sci. Rep. 10 (1), 13551. doi:10.1038/s41598-020-70309-2

Harvey, A. J. (2019). Mitochondria in early development: linking the microenvironment, metabolism and the epigenome. Reproduction. 157 (5), R159-R179. doi:10.1530/rep-18-0431 
He, L., Ling, L., Wei, T., Wang, Y., and Xiong, Z. (2017). Ginsenoside Rg1 improves fertility and reduces ovarian pathological damages in premature ovarian failure model of mice. Exp. Biol. Med. 242 (7), 683-691. doi:10.1177/ 1535370217693323

He, Q., Du, B., and Xu, B. (2018). Extraction optimization of phenolics and antioxidants from black goji berry by accelerated solvent extractor using response surface methodology. Appl. Sci. 8, 1905. doi:10.3390/app8101905

Heidinger, B. J., Blount, J. D., Boner, W., Griffiths, K., Metcalfe, N. B., and Monaghan, P. (2012). Telomere length in early life predicts lifespan. Proc. Natl. Acad. Sci. U.S.A. 109 (5), 1743-1748. doi:10.1073/pnas.1113306109

Hu, K. L., Ye, X., Wang, S., and Zhang, D. (2020). Melatonin application in assisted reproductive technology: a systematic review and meta-analysis of randomized trials. Front. Endocrinol. 11, 160. doi:10.3389/fendo.2020.00160

Hua, S., Zhang, Y., Li, X. C., Ma, L. B., Cao, J. W., Dai, J. P., et al. (2007). Effects of granulosa cell mitochondria transfer on the early development of bovine embryos in vitro. Clon. Stem Cell 9 (2), 237-246. doi:10.1089/clo. 2006.0020

Huang, J., Okuka, M., McLean, M., Keefe, D. L., and Liu, L. (2009). Effects of cigarette smoke on fertilization and embryo development in vivo. Fertil. Steril. 92 (4), 1456-1465. doi:10.1016/j.fertnstert.2008.07.1781

Huang, J., Okuka, M., McLean, M., Keefe, D. L., and Liu, L. (2010). Telomere susceptibility to cigarette smoke-induced oxidative damage and chromosomal instability of mouse embryos in vitro. Free Radic. Biol. Med. 48 (12), 1663-1676. doi:10.1016/j.freeradbiomed.2010.03.026

Huang, K., Zhang, J., O’Neill, K. L., Gurumurthy, C. B., Quadros, R. M., Tu, Y., et al. (2016). Cleavage by caspase 8 and mitochondrial membrane association activate the BH3-only protein Bid during TRAIL-induced apoptosis. J. Biol. Chem. 291 (22), 11843-11851. doi:10.1074/jbc.M115.711051

Huang, M. L., Chiang, S., Kalinowski, D. S., Bae, D. H., Sahni, S., and Richardson, D. R. (2019). The role of the antioxidant response in mitochondrial dysfunction in degenerative diseases: cross-talk between antioxidant defense, autophagy, and apoptosis. Oxid. Med. Cell Longev. 2019, 6392763. doi:10.1155/2019/ 6392763

Huang, Y., Hu, C., Ye, H., Luo, R., Fu, X., Li, X., et al. (2019). Inflamm-aging: a new mechanism affecting premature ovarian insufficiency. J. Immunol. Res. 2019, 8069898. doi:10.1155/2019/8069898

Ighodaro, O. M., and Akinloye, O. A. (2018). First line defence antioxidantssuperoxide dismutase (SOD), catalase (CAT) and glutathione peroxidase (GPX): their fundamental role in the entire antioxidant defence grid. Alexandria J. Med. 54 (4), 287-293. doi:10.1016/j.ajme.2017.09.001

Itami, N., Shirasuna, K., Kuwayama, T., and Iwata, H. (2015). Resveratrol improves the quality of pig oocytes derived from early antral follicles through sirtuin 1 activation. Theriogenology 83 (8), 1360-1367. doi:10.1016/j.theriogenology. 2015.01.029

Itkin, M., Davidovich-Rikanati, R., Cohen, S., Portnoy, V., Doron-Faigenboim, A., Oren, E., et al. (2016). The biosynthetic pathway of the nonsugar, high-intensity sweetener mogroside V from Siraitia grosvenorii. Proc. Natl. Acad. Sci. U.S.A. 113 (47), E7619-E7628. doi:10.1073/pnas.1604828113

Ito, J., Shirasuna, K., Kuwayama, T., and Iwata, H. (2020). Resveratrol treatment increases mitochondrial biogenesis and improves viability of porcine germinalvesicle stage vitrified-warmed oocytes. Cryobiology 93, 37-43. doi:10.1016/j. cryobiol.2020.02.014

Jahromi, B. N., Sadeghi, S., Alipour, S., Parsanezhad, M. E., and Alamdarloo, S. M. (2017). Effect of melatonin on the outcome of assisted reproductive technique cycles in women with diminished ovarian reserve: a double-blinded randomized clinical trial. Iran. J. Med. Sci. 42 (1), 73-78.

James, S. M., Honn, K. A., Gaddameedhi, S., and Van Dongen, H. P. A. (2017). Shift work: disrupted circadian rhythms and sleep-implications for health and wellbeing. Curr. Sleep Med. Rep. 3 (2), 104-112. doi:10.1007/s40675-017-0071-6

Jiang, B., Shen, R. F., Bi, J., Tian, X. S., Hinchliffe, T., and Xia, Y. (2015). Catalpol: a potential therapeutic for neurodegenerative diseases. Curr. Med. Chem. 22 (10), 1278-1291. doi:10.2174/0929867322666150114151720

Jiang, Y., Zhang, Z., Cha, L., Li, L., Zhu, D., Fang, Z., et al. (2019). Resveratrol plays a protective role against premature ovarian failure and prompts female germline stem cell survival. Int. J. Mol. Sci. 20 (14), 3605. doi:10.3390/ ijms20143605

Kaarniranta, K., Pawlowska, E., Szczepanska, J., Jablkowska, A., and Blasiak, J. (2019). Role of mitochondrial DNA damage in ROS-mediated pathogenesis of age-related macular degeneration (AMD). Int. J. Mol. Sci. 20 (10), 2374. doi:10. 3390/ijms20102374

Kamat, P. K., Kalani, A., Rai, S., Swarnkar, S., Tota, S., Nath, C., et al. (2016). Mechanism of oxidative stress and synapse dysfunction in the pathogenesis of alzheimer's disease: understanding the therapeutics strategies. Mol. Neurobiol. 53 (1), 648-661. doi:10.1007/s12035-014-9053-6

Kasapoğlu, I., and Seli, E. (2020). Mitochondrial dysfunction and ovarian aging. Endocrinology 161 (2), bqaa001. doi:10.1210/endocr/bqaa001

Kauppila, T. E. S., Kauppila, J. H. K., and Larsson, N. G. (2017). Mammalian mitochondria and aging: an update Cell Metabol. 25 (1), 57-71. doi:10.1016/j. cmet.2016.09.017

Keefe, D. L., Liu, L., and Marquard, K. (2007). Telomeres and aging-related meiotic dysfunction in women. Cell. Mol. Life Sci. 64 (2), 139-143. doi:10.1007/s00018006-6466-z

Khadrawy, O., Gebremedhn, S., Salilew-Wondim, D., Taqi, M. O., Neuhoff, C., Tholen, E., et al. (2019). Endogenous and exogenous modulation of Nrf2 mediated oxidative stress response in bovine granulosa cells: potential implication for ovarian function. Int. J. Mol. Sci. 20 (7), 1635. doi:10.3390/ ijms 20071635

Kim, C. W., Go, R. E., Hwang, K. A., Bae, O. N., Lee, K., and Choi, K. C. (2018), Effects of cigarette smoke extracts on apoptosis and oxidative stress in two models of ovarian cancer in vitro. Toxicol. Vitro. 52, 161-169. doi:10.1016/j.tiv. 2018.06.007

Kocaadam, B., and Șanlier, N. (2017). Curcumin, an active component of turmeric (Curcuma longa), and its effects on health. Crit. Rev. Food Sci. Nutr. 57 (13), 2889-2895. doi:10.1080/10408398.2015.1077195

Kong, Q. Q., Wang, J., Xiao, B., Lin, F. H., Zhu, J., Sun, G. Y., et al. (2018). Cumulus cell-released tumor necrosis factor (TNF)- $\alpha$ promotes post-ovulatory aging of mouse oocytes. Aging 10 (7), 1745-1757. doi:10.18632/aging.101507

Kotha, R. R., and Luthria, D. L. (2019). Curcumin: biological, pharmaceutical, nutraceutical, and analytical aspects. Molecules. 24 (16), 2930. doi:10.3390/ molecules 24162930

Kristensen, S. G., Pors, S. E., and Andersen, C. Y. (2017). Improving oocyte quality by transfer of autologous mitochondria from fully grown oocytes. Hum. Reprod. 32 (4), 725-732. doi:10.1093/humrep/dex043

Krysko, D. V., Diez-Fraile, A., Criel, G., Svistunov, A. A., Vandenabeele, P., and D'Herde, K. (2008). Life and death of female gametes during oogenesis and folliculogenesis. Apoptosis 13 (9), 1065-1087. doi:10.1007/s10495-008-0238-1

Labarta, E., de Los Santos, M. J., Escribá, M. J., Pellicer, A., and Herraiz, S. (2019). Mitochondria as a tool for oocyte rejuvenation. Fertil. Steril. 111 (2), 219-226. doi:10.1016/j.fertnstert.2018.10.036

Leone, S., Recinella, L., Chiavaroli, A., Orlando, G., Ferrante, C., Leporini, L., et al. (2018). Phytotherapic use of the Crocus sativus L. (Saffron) and its potential applications: a brief overview. Phytother Res. 32 (12), 2364-2375. doi:10.1002/ ptr.6181

$\mathrm{Li}, \mathrm{N}$., and Liu, L. (2018). Mechanism of resveratrol in improving ovarian function in a rat model of premature ovarian insufficiency. J. Obstet. Gynaecol. Res. 44 (8), 1431-1438. doi:10.1111/jog.13680

Li, F., Ding, J., Cong, Y., Liu, B., Miao, J., Wu, D., et al. (2020). Trichostatin A alleviated ovarian tissue damage caused by cigarette smoke exposure. Reprod. Toxicol. 93, 89-98. doi:10.1016/j.reprotox.2020.01.006

Li, S., Hong, M., Tan, H. Y., Wang, N., and Feng, Y. (2016). Insights into the role and interdependence of oxidative stress and inflammation in liver diseases. Oxid. Med. Cell Longev. 2016, 4234061. doi:10.1155/2016/4234061

Li, Y., Yao, J., Han, C., Yang, J., Chaudhry, M. T., Wang, S., et al. (2016). Quercetin, inflammation and immunity. Nutrients 8 (3), 167. doi:10.3390/nu8030167

Liang, X., Zhang, D., Liu, W., Yan, Y., Zhou, F., Wu, W., et al. (2017). Reactive oxygen species trigger NF- $\mathrm{KB}$-mediated NLRP3 inflammasome activation induced by zinc oxide nanoparticles in A549 cells. Toxicol. Ind. Health. 33 (10), 737-745. doi:10.1177/0748233717712409

Liguori, I., Russo, G., Curcio, F., Bulli, G., Aran, L., Della-Morte, D., et al. (2018). Oxidative stress, aging, and diseases. Clin. Interv. Aging 13, 757-772. doi:10. 2147/cia.S158513

Lim, J., and Luderer, U. (2011). Oxidative damage increases and antioxidant gene expression decreases with aging in the mouse ovary. Biol. Reprod. 84 (4), 775-782. doi:10.1095/biolreprod.110.088583

Liochev, S. I. (2013). Reactive oxygen species and the free radical theory of aging. Free Radic. Biol. Med. 60, 1-4. doi:10.1016/j.freeradbiomed.2013.02.011 
Liu, C., Dai, L., Liu, Y., Dou, D., Sun, Y., and Ma, L. (2018). Pharmacological activities of mogrosides. Future Med. Chem. 10 (8), 845-850. doi:10.4155/fmc2017-0255

Liu, H., Wang, C., Qi, X., Zou, J., and Sun, Z. (2018). Antiglycation and antioxidant activities of mogroside extract from Siraitia grosvenorii (Swingle) fruits. J. Food Sci. Technol. 55 (5), 1880-1888. doi:10.1007/s13197-018-3105-2

Liu, M., Yin, Y., Ye, X., Zeng, M., Zhao, Q., Keefe, D. L., et al. (2013). Resveratrol protects against age-associated infertility in mice. Hum. Reprod. 28 (3), 707-717. doi:10.1093/humrep/des437

Liu, T., Li, N., Yan, Y. Q., Liu, Y., Xiong, K., Liu, Y., et al. (2020). Recent advances in the anti-aging effects of phytoestrogens on collagen, water content, and oxidative stress. Phytother. Res. 34 (3), 435-447. doi:10.1002/ptr.6538

Liu, T., Zhang, L., Joo, D., and Sun, S. C. (2017). NF-kB signaling in inflammation. Signal Transduct. Target Ther. 2, 17023. doi:10.1038/sigtrans.2017.23

Liu, X., Lin, X., Mi, Y., Li, J., and Zhang, C. (2018). Grape seed proanthocyanidin extract prevents ovarian aging by inhibiting oxidative stress in the hens. Oxid. Med. Cell Longev. 2018, 9390810. doi:10.1155/2018/9390810

Liu, Y., Wang, Y. L., He, S. W., Chen, M. H., Zhang, Z., Fu, X. P., et al. (2017). Protective effects of resveratrol against mancozeb induced apoptosis damage in mouse oocytes. Oncotarget 8 (4), 6233-6245. doi:10.18632/oncotarget.14056

Long, Y., Liu, X., Tan, X. Z., Jiang, C. X., Chen, S. W., Liang, G. N., et al. (2020). ROS-induced NLRP3 inflammasome priming and activation mediate PCB 118induced pyroptosis in endothelial cells. Ecotoxicol. Environ. Saf. 189, 109937. doi:10.1016/j.ecoenv.2019.109937

López-Otín, C., Blasco, M. A., Partridge, L., Serrano, M., and Kroemer, G. (2013). The hallmarks of aging. Cell 153 (6), 1194-1217. doi:10.1016/j.cell.2013.05.039

Lord, T., Martin, J. H., and Aitken, R. J. (2015). Accumulation of electrophilic aldehydes during postovulatory aging of mouse oocytes causes reduced fertility, oxidative stress, and apoptosis. Biol. Reprod. 92 (2), 33. doi:10.1095/biolreprod. 114.122820

Lu, J., Wang, Z., Cao, J., Chen, Y., and Dong, Y. (2018). A novel and compact review on the role of oxidative stress in female reproduction. Reprod. Biol. Endocrinol. 16 (1), 80. doi:10.1186/s12958-018-0391-5

Lutz-Bonengel, S., and Parson, W. (2019). No further evidence for paternal leakage of mitochondrial DNA in humans yet. Proc. Natl. Acad. Sci. U.S.A. 116 (6), 1821-1822. doi:10.1073/pnas.1820533116

Maclaran, K., and Nikolaou, D. (2019). Early ovarian ageing. Obstet. Gynaecol. 21 (2), 107-116. doi:10.1111/tog.12558

Mahdi, H., Tahereh, H., Esmaiel, S., and Massood, E. (2019). Vitamins E and C prevent apoptosis of testicular and ovarian tissues following mancozeb exposure in the first-generation mouse pups. Toxicol. Ind. Health. 35 (2), 136-144. doi:10.1177/0748233718818692

Mai, Z., Lei, M., Yu, B., Du, H., and Liu, J. (2014). The effects of cigarette smoke extract on ovulation, oocyte morphology and ovarian gene expression in mice. PLoS One 9 (4), e95945. doi:10.1371/journal.pone.0095945

Mason, J. B., Cargill, S. L., Griffey, S. M., Reader, J. R., Anderson, G. B., and Carey, J. R. (2011). Transplantation of young ovaries restored cardioprotective influence in postreproductive-aged mice. Aging Cell 10 (3), 448-456. doi:10. 1111/j.1474-9726.2011.00691.x

Mason, J. B., Parkinson, K. C., and Habermehl, T. L. (2018). Orthotopic ovarian transplantation procedures to investigate the life- and health-span influence of ovarian senescence in female mice. J. Vis. Exp. 132, 56638. doi:10.3791/56638

Matos, L., Stevenson, D., Gomes, F., Silva-Carvalho, J. L., and Almeida, H. (2009). Superoxide dismutase expression in human cumulus oophorus cells. Mol. Hum. Reprod. 15 (7), 411-419. doi:10.1093/molehr/gap034

May-Panloup, P., Boucret, L., Chao de la Barca, J.-M., Desquiret-Dumas, V., FerréL'Hotellier, V., Morinière, C., et al. (2016). Ovarian ageing: the role of mitochondria in oocytes and follicles. Hum. Reprod. Update 22 (6), 725-743. doi:10.1093/humupd/dmw028

Melekoglu, R., Ciftci, O., Eraslan, S., Cetin, A., and Basak, N. (2018). Beneficial effects of curcumin and capsaicin on cyclophosphamide-induced premature ovarian failure in a rat model. J. Ovarian Res. 11 (1), 33. doi:10.1186/s13048018-0409-9

Meng, X., Zhou, J., Zhao, C. N., Gan, R. Y., and Li, H. B. (2020). Health benefits and molecular mechanisms of resveratrol: a narrative review. Foods 9 (3), 340. doi:10.3390/foods 9030340

Miao, Y., Zhou, C., Cui, Z., Zhang, M., ShiYang, X., Lu, Y., et al. (2018). Postovulatory aging causes the deterioration of porcine oocytes via induction of oxidative stress. Faseb. J. 32 (3), 1328-1337. doi:10.1096/fj. 201700908R

Mohammadi, S., Kayedpoor, P., Karimzadeh-Bardei, L., and Nabiuni, M. (2017). The effect of curcumin on TNF- $\alpha$, IL- 6 and CRP expression in a model of polycystic ovary syndrome as an inflammation state. J. Reprod. Infertil. 18 (4), 352-360.

Mokhber Maleki, E., Eimani, H., Bigdeli, M. R., Ebrahimi, B., Shahverdi, A. H., Golkar Narenji, A., et al. (2014). A comparative study of saffron aqueous extract and its active ingredient, crocin on the in vitro maturation, in vitro fertilization, and in vitro culture of mouse oocytes. Taiwan. J. Obstet. Gynecol. 53 (1), 21-25. doi:10.1016/j.tjog.2012.11.004

Mokhber Maleki, E., Eimani, H., Bigdeli, M. R., Golkar Narenji, A., and Abedi, R. (2016). Effects of crocin supplementation during in vitro maturation of mouse oocytes on glutathione synthesis and cytoplasmic maturation. Int. J. Fertil. Steril. 10 (1), 53-61. doi:10.22074/ijfs.2016.4769

Monian, P., and Jiang, X. (2012). Clearing the final hurdles to mitochondrial apoptosis: regulation post cytochrome C release. Exp. Oncol. 34 (3), 185-191.

Morgan, M. J., Kim, Y.-S., and Liu, Z.-g. (2008). TNFa and reactive oxygen species in necrotic cell death. Cell Res. 18 (3), 343-349. doi:10.1038/cr.2008.31

Murphy, M. P. (2012). Modulating mitochondrial intracellular location as a redox signal. Sci. Signal. 5 (242), pe39. doi:10.1126/scisignal.2003386

Navarro-Pando, J. M., Alcocer-Gómez, E., Castejon Vega, B., Muntané, J., Bullon, P., Wang, C., et al. (2020). Inhibition of the NLRP3 inflammasome prevents ovarian aging. bioRxiv. doi:10.1101/2020.04.26.062646

Nie, J., Sui, L., Zhang, H., Zhang, H., Yan, K., Yang, X., et al. (2019). Mogroside V protects porcine oocytes from in vitro ageing by reducing oxidative stress through SIRT1 upregulation. Aging (Albany NY). 11 (19), 8362-8373. doi:10. 18632/aging.102324

Nie, J., Yan, K., Sui, L., Zhang, H., Zhang, H., Yang, X., et al. (2020). Mogroside V improves porcine oocyte in vitro maturation and subsequent embryonic development. Theriogenology 141, 35-40. doi:10.1016/j.theriogenology.2019. 09.010

Niemann, B., Rohrbach, S., Miller, M. R., Newby, D. E., Fuster, V., and Kovacic, J. C. (2017). Oxidative stress and cardiovascular risk: obesity, diabetes, smoking, and pollution: Part 3 of a 3-Part Series. J. Am. Coll. Cardiol. 70 (2), 230-251. doi:10.1016/j.jacc.2017.05.043

Nna, V. U., Usman, U. Z., Ofutet, E. O., and Owu, D. U. (2017). Quercetin exerts preventive, ameliorative and prophylactic effects on cadmium chloride induced oxidative stress in the uterus and ovaries of female Wistar rats. Food Chem. Toxicol. 102, 143-155. doi:10.1016/j.fct.2017.02.010

Oktay, K., Baltaci, V., Sonmezer, M., Turan, V., Unsal, E., Baltaci, A., et al. (2015). Oogonial precursor cell-derived autologous mitochondria injection to improve outcomes in women with multiple IVF failures due to low oocyte quality: a clinical translation. Reprod. Sci. 22 (12), 1612-1617. doi:10.1177/ 1933719115612137

Oyawoye, O., Abdel Gadir, A., Garner, A., Constantinovici, N., Perrett, C., and Hardiman, P. (2003). Antioxidants and reactive oxygen species in follicular fluid of women undergoing IVF: relationship to outcome. Hum. Reprod. 18 (11), 2270-2274. doi:10.1093/humrep/deg450

Ozatik, F. Y., Ozatik, O., Yigitaslan, S., Kaygısız, B., and Erol, K. (2020). Do resveratrol and dehydroepiandrosterone increase diminished ovarian reserve? Eurasian J. Med. 52 (1), 6-11. doi:10.5152/eurasianjmed.2019.19044

Park, C., Cha, H. J., Lee, H., Hwang-Bo, H., Ji, S. Y., Kim, M. Y., et al. (2019). Induction of $\mathrm{G} 2 / \mathrm{M}$ cell cycle arrest and apoptosis by genistein in human bladder cancer T24 cells through inhibition of the ROS-dependent PI3k/akt signal transduction pathway. Antioxidants 8 (9), 327. doi:10.3390/ antiox 8090327

Parkinson, K. C., Peterson, R. L., and Mason, J. B. (2017). Cognitive behavior and sensory function were significantly influenced by restoration of active ovarian function in postreproductive mice. Exp. Gerontol. 92, 28-33. doi:10.1016/j. exger.2017.03.002

Pasquariello, R., Ermisch, A. F., Silva, E., McCormick, S., Logsdon, D., Barfield, J. P., et al. (2019). Alterations in oocyte mitochondrial number and function are related to spindle defects and occur with maternal aging in mice and humans $\dagger$. Biol. Reprod. 100 (4), 971-981. doi:10.1093/biolre/ioy248

Peters, A. E., Mihalas, B. P., Bromfield, E. G., Roman, S. D., Nixon, B., and Sutherland, J. M. (2020). Autophagy in female fertility: a role in oxidative stress and aging. Antioxid Redox Signal. 32 (8), 550-568. doi:10.1089/ars.2019.7986 
Peterson, R. L., Parkinson, K. C., and Mason, J. B. (2017). Restoration of immune and renal function in aged females by re-establishment of active ovarian function. Reprod. Fertil. Dev. 29 (10), 2052-2059. doi:10.1071/rd16333

Pineda-Pampliega, J., Herrera-Dueñas, A., Mulder, E., Aguirre, J. I., Höfle, U., and Verhulst, S. (2020). Antioxidant supplementation slows telomere shortening in free-living white stork chicks. Proc. Biol. Sci. 287 (1918), 20191917. doi:10.1098/ rspb.2019.1917

Pinto, M., and Moraes, C. T. (2015). Mechanisms linking mtDNA damage and aging. Free Radic. Biol. Med. 85, 250-258. doi:10.1016/j.freeradbiomed.2015. 05.005

Piras, A. R., Menéndez-Blanco, I., Soto-Heras, S., Catalá, M. G., Izquierdo, D., Bogliolo, L., et al. (2019). Resveratrol supplementation during in vitro maturation improves embryo development of prepubertal goat oocytes selected by brilliant cresyl blue staining. J. Reprod. Dev. 65 (2), 113-120. doi:10.1262/jrd.2018-077

Prasad, K. N., Wu, M., and Bondy, S. C. (2017). Telomere shortening during aging: attenuation by antioxidants and anti-inflammatory agents. Mech. Ageing Develop. 164, 61-66. doi:10.1016/j.mad.2017.04.004

Prasad, S., Tiwari, M., Pandey, A. N., Shrivastav, T. G., and Chaube, S. K. (2016). Impact of stress on oocyte quality and reproductive outcome. J. Biomed. Sci. 23, 36. doi:10.1186/s12929-016-0253-4

Premkumar, K. V., and Chaube, S. K. (2015). Nitric oxide signals postovulatory aging-induced abortive spontaneous egg activation in rats. Redox Rep. 20 (4), 184-192. doi:10.1179/1351000215y.0000000003

Qin, J., Wang, W., and Zhang, R. (2017). Novel natural product therapeutics targeting both inflammation and cancer. Chin. J. Nat. Med. 15 (6), 401-416. doi:10.1016/s1875-5364(17)30062-6

Qin, X., Cao, M., Lai, F., Yang, F., Ge, W., Zhang, X., et al. (2015). Oxidative stress induced by zearalenone in porcine granulosa cells and its rescue by curcumin in vitro. PLoS One 10 (6), e0127551. doi:10.1371/journal.pone.0127551

Quinn, M. M., and Cedars, M. I. (2018). Cardiovascular health and ovarian aging. Fertil. Steril. 110 (5), 790-793. doi:10.1016/j.fertnstert.2018.07.1152

Racchi, M. L. (2013). Antioxidant defenses in plants with attention to prunus and citrus spp. Antioxidants 2 (4), 340-369. doi:10.3390/antiox2040340

Rajkovic, A., and Pangas, S. (2017). Ovary as a biomarker of health and longevity: insights from genetics. Semin. Reprod. Med. 35 (3), 231-240. doi:10.1055/s0037-1603571

Rashidi, Z., Aleyasin, A., Eslami, M., Nekoonam, S., Zendedel, A., Bahramrezaie, M., et al. (2019). Quercetin protects human granulosa cells against oxidative stress via thioredoxin system. Reprod. Biol. 19 (3), 245-254. doi:10.1016/j. repbio.2019.07.002

Redza-Dutordoir, M., and Averill-Bates, D. A. (2016). Activation of apoptosis signalling pathways by reactive oxygen species. Biochim. Biophys. Acta Mol. Cell Res. 1863 (12), 2977-2992. doi:10.1016/j.bbamcr.2016.09.012

Regan, S. L. P., Knight, P. G., Yovich, J. L., Leung, Y., Arfuso, F., and Dharmarajan, A. (2018a). Granulosa cell apoptosis in the ovarian follicle-A changing view. Front. Endocrinol. 9, 61. doi:10.3389/fendo.2018.00061

Regan, S. L. P., Knight, P. G., Yovich, J. L., Stanger, J. D., Leung, Y., Arfuso, F., et al. (2018b). The effect of ovarian reserve and receptor signalling on granulosa cell apoptosis during human follicle development. Mol. Cell. Endocrinol. 470, 219-227. doi:10.1016/j.mce.2017.11.002

Rizzo, A., Roscino, M. T., Binetti, F., and Sciorsci, R. L. (2012). Roles of reactive oxygen species in female reproduction. Reprod. Domest. Anim. 47 (2), 344-352. doi:10.1111/j.1439-0531.2011.01891.x

Ross, J. M., Coppotelli, G., Hoffer, B. J., and Olson, L. (2014). Maternally transmitted mitochondrial DNA mutations can reduce lifespan. Sci. Rep. 4 (1), 6569. doi:10.1038/srep06569

Sadraie, S. H., Saito, H., Kaneko, T., Saito, T., and Hiroi, M. (2000). Effects of aging on ovarian fecundity in terms of the incidence of apoptotic granulosa cells. J. Assist. Reprod. Genet. 17 (3), 168-173. doi:10.1023/a:1009422323306

Saha, S. K., Lee, S. B., Won, J., Choi, H. Y., Kim, K., Yang, G. M., et al. (2017). Correlation between oxidative stress, nutrition, and cancer initiation. Int. J. Mol. Sci. 18 (7), 1544. doi:10.3390/ijms18071544

Said, R. S., El-Demerdash, E., Nada, A. S., and Kamal, M. M. (2016). Resveratrol inhibits inflammatory signaling implicated in ionizing radiation-induced premature ovarian failure through antagonistic crosstalk between silencing information regulator 1 (SIRT1) and poly(ADP-ribose) polymerase 1 (PARP1). Biochem. Pharmacol. 103, 140-150. doi:10.1016/j.bcp.2016.01.019
Said, R. S., Mantawy, E. M., and El-Demerdash, E. (2019). Mechanistic perspective of protective effects of resveratrol against cisplatin-induced ovarian injury in rats: emphasis on anti-inflammatory and anti-apoptotic effects. NaunynSchmiedeberg's Arch. Pharmacol. 392 (10), 1225-1238. doi:10.1007/s00210019-01662-x

Sak, M. E., Soydinc, H. E., Sak, S., Evsen, M. S., Alabalik, U., Akdemir, F., et al. (2013). The protective effect of curcumin on ischemia-reperfusion injury in rat ovary. Int. J. Surg. 11 (9), 967-970. doi:10.1016/j.ijsu.2013. 06.007

Saleh, D. O., and Mansour, D. F. (2016). Ovario-protective effects of genistein against cyclophosphamide toxicity in rats: role of anti-müllerian hormone and oestradiol. Eur. J. Pharmacol. 789, 163-171. doi:10.1016/j.ejphar.2016. 07.026

Sasaki, H., Hamatani, T., Kamijo, S., Iwai, M., Kobanawa, M., Ogawa, S., et al. (2019). Impact of oxidative stress on age-associated decline in oocyte developmental competence. Front. Endocrinol. 10, 811. doi:10.3389/fendo. 2019.00811

Scialò, F., Fernández-Ayala, D. J., and Sanz, A. (2017). Role of mitochondrial reverse electron transport in ROS signaling: potential roles in health and disease. Front. Physiol. 8, 428. doi:10.3389/fphys.2017.00428

Shi, J., Yu, J., Pohorly, J. E., and Kakuda, Y. (2003). Polyphenolics in grape seedsbiochemistry and functionality. J. Med. Food 6 (4), 291-299. doi:10.1089/ 109662003772519831

Shi, L., Zhang, J., Lai, Z., Tian, Y., Fang, L., Wu, M., et al. (2016). Long-term moderate oxidative stress decreased ovarian reproductive function by reducing follicle quality and progesterone production. PLoS One 11 (9), e0162194. doi:10. 1371/journal.pone.0162194

Silva, A. A. A., Silva, M. N. P., Figueiredo, L. B. F., Gonçalves, J. D., Silva, M. J. S., Loiola, M. L. G., et al. (2018). Quercetin influences in vitro maturation, apoptosis and metabolically active mitochondria of goat oocytes. Zygote 26 (6), 465-470. doi:10.1017/s0967199418000485

Singh, A., Kukreti, R., Saso, L., and Kukreti, S. (2019). Oxidative stress: role and response of short guanine tracts at genomic locations. Int. J. Mol. Sci. 20 (17), 4258. doi:10.3390/ijms20174258

Smith, S. (2018). Telomerase can't handle the stress. Genes Dev. 32 (9-10), 597-599. doi:10.1101/gad.316042.118

Smith, E. M., Pendlebury, D. F., and Nandakumar, J. (2020). Structural biology of telomeres and telomerase. Cell. Mol. Life Sci. 77 (1), 61-79. doi:10.1007/s00018019-03369-x

Snider, A. P., and Wood, J. R. (2019). Obesity induces ovarian inflammation and reduces oocyte quality. Reproduction. 158 (3), R79-R90. doi:10.1530/rep-18-0583

Sobinoff, A. P., Beckett, E. L., Jarnicki, A. G., Sutherland, J. M., McCluskey, A., Hansbro, P. M., et al. (2013). Scrambled and fried: cigarette smoke exposure causes antral follicle destruction and oocyte dysfunction through oxidative stress. Toxicol. Appl. Pharmacol. 271 (2), 156-167. doi:10.1016/j.taap.2013. 05.009

Sohel, M. M. H., Akyuz, B., Konca, Y., Arslan, K., Sariozkan, S., and Cinar, M. U. (2019). Oxidative stress modulates the expression of apoptosis-associated microRNAs in bovine granulosa cells in vitro. Cell Tissue Res. 376 (2), 295-308. doi:10.1007/s00441-019-02990-3

Spagnuolo, C., Russo, G. L., Orhan, I. E., Habtemariam, S., Daglia, M., Sureda, A., et al. (2015). Genistein and cancer: current status, challenges, and future directions. Adv. Nutr. 6 (4), 408-419. doi:10.3945/an.114.008052

Srirattana, K., and St John, J. C. (2018). Additional mitochondrial DNA influences the interactions between the nuclear and mitochondrial genomes in a bovine embryo model of nuclear transfer. Sci. Rep. 8 (1), 7246. doi:10.1038/s41598018-25516-3

Steven, S., Frenis, K., Oelze, M., Kalinovic, S., Kuntic, M., Bayo Jimenez, M. T., et al. (2019). Vascular inflammation and oxidative stress: major triggers for cardiovascular disease. Oxid. Med. Cell Longev. 2019, 7092151. doi:10.1155/ 2019/7092151

Stock, D., Knight, J. A., Raboud, J., Cotterchio, M., Strohmaier, S., Willett, W., et al. (2019). Rotating night shift work and menopausal age. Hum. Reprod. 34 (3), 539-548. doi:10.1093/humrep/dey390

Sugino, N. (2005). Reactive oxygen species in ovarian physiology. Reprod. Med. Biol. 4 (1), 31-44. doi:10.1007/bf03016135

Sugiyama, M., Kawahara-Miki, R., Kawana, H., Shirasuna, K., Kuwayama, T., and Iwata, H. (2015). Resveratrol-induced mitochondrial synthesis and autophagy 
in oocytes derived from early antral follicles of aged cows. J. Reprod. Dev. 61 (4), 251-259. doi:10.1262/jrd.2015-001

Sun, S., Chen, H., Zheng, X., Ma, C., and Yue, R. (2018). Analysis on the level of IL6, IL-21, AMH in patients with auto-immunity premature ovarian failure and study of correlation. Exp. Ther. Med. 16 (4), 3395-3398. doi:10.3892/etm.2018. 6592

Sun, Y. L., Tang, S. B., Shen, W., Yin, S., and Sun, Q. Y. (2019). Roles of resveratrol in improving the quality of postovulatory aging oocytes in vitro. Cells 8 (10), 1132. doi:10.3390/cells 8101132

Takeo, S., Kimura, K., Shirasuna, K., Kuwayama, T., and Iwata, H. (2017). Ageassociated deterioration in follicular fluid induces a decline in bovine oocyte quality. Reprod. Fertil. Dev. 29 (4), 759-767. doi:10.1071/rd15228

Tang, H., Wang, S., Li, X., Zou, T., Huang, X., Zhang, W., et al. (2019). Molecular mechanisms of action of genistein in cancer: recent advances. Front. Pharmacol. 27 (149), 177-188.

Tardat, M., and Déjardin, J. (2018). Telomere chromatin establishment and its maintenance during mammalian development. Chromosoma. 127 (1), 3-18. doi:10.1007/s00412-017-0656-3

Tatone, C., Carbone, M. C., Falone, S., Aimola, P., Giardinelli, A., Caserta, D., et al. (2006). Age-dependent changes in the expression of superoxide dismutases and catalase are associated with ultrastructural modifications in human granulosa cells. Mol. Hum. Reprod. 12 (11), 655-660. doi:10.1093/molehr/gal080

Teixeira, F. K., Sanchez, C. G., Hurd, T. R., Seifert, J. R., Czech, B., Preall, J. B., et al. (2015). ATP synthase promotes germ cell differentiation independent of oxidative phosphorylation. Nat. Cell Biol. 17 (5), 689-696. doi:10.1038/ncb3165

Teixeira, K. R. C., dos Santos, C. P., de Medeiros, L. A., Mendes, J. A., Cunha, T. M., De Angelis, K., et al. (2019). Night workers have lower levels of antioxidant defenses and higher levels of oxidative stress damage when compared to day workers. Sci. Rep. 9 (1), 4455. doi:10.1038/s41598-019-40989-6

Tiwari, M., Prasad, S., Tripathi, A., Pandey, A. N., Ali, I., Singh, A. K., et al. (2015). Apoptosis in mammalian oocytes: a review. Apoptosis. 20 (8), 1019-1025. doi:10.1007/s10495-015-1136-y

Tiwari, M., Prasad, S., Tripathi, A., Pandey, A. N., Singh, A., Shrivastav, T., et al. (2016). Involvement of reactive oxygen species in meiotic cell cycle regulation and apoptosis in mammalian oocytes. React. Oxygen Species 1, 99-106. doi:10. 20455/ros.2016.817

Tong, J., Gao, J., Liu, Q., He, C., Zhao, X., Qi, Y., et al. (2020). Resveratrol derivative excited postsynaptic potentiation specifically via $\mathrm{PKC} \beta$-NMDA receptor mediation. Pharmacol. Res. 152, 104618. doi:10.1016/j.phrs.2019.104618

Tong, S., Chen, L., Zhang, Q., Liu, J., Yan, J., and Ito, Y. (2015). Separation of catalpol from Rehmannia glutinosa Libosch. by high-speed countercurrent chromatography. J. Chromatogr. Sci. 53 (5), 725-729. doi:10.1093/chromsci/ bmul14

Tripathi, A., Shrivastav, T. G., and Chaube, S. K. (2013). An increase of granulosa cell apoptosis mediates aqueous neem (Azadirachta indica) leaf extract-induced oocyte apoptosis in rat. Int. J. Appl. Basic Med. Res. 3 (1), 27-36. doi:10.4103/ 2229-516x.112238

Tsiligiannis, S., Panay, N., and Stevenson, J. C. (2019). Premature ovarian insufficiency and long-term health consequences. Curr. Vasc. Pharmacol. 17 (6), 604-609. doi:10.2174/1570161117666190122101611

Turner, K. J., Vasu, V., and Griffin, D. K. (2019). Telomere biology and human phenotype. Cells 8 (1), 73. doi:10.3390/cells8010073

Wang, H., Jo, Y. J., Oh, J. S., and Kim, N. H. (2017). Quercetin delays postovulatory aging of mouse oocytes by regulating SIRT expression and MPF activity. Oncotarget 8 (24), 38631-38641. doi:10.18632/oncotarget.16219

Wang, J.-L., Liu, B., Zhang, C., Wang, X.-M., Zhen, D., Huang, X.-M., et al. (2019). Effects of icariin on ovarian function in d-galactose-induced aging mice. Theriogenology 125, 157-167. doi:10.1016/j.theriogenology.2018.10.028

Wang, S., He, G., Chen, M., Zuo, T., Xu, W., and Liu, X. (2017). The role of antioxidant enzymes in the ovaries. Oxid. Med. Cell Longev. 2017, 4371714. doi:10.1155/2017/4371714

Wang, S., Zheng, Y., Li, J., Yu, Y., Zhang, W., Song, M., et al. (2020). Single-cell transcriptomic atlas of primate ovarian aging. Cell 180 (3), 585-600.e519. doi:10.1016/j.cell.2020.01.009

Wang, T., Zhang, M., Jiang, Z., and Seli, E. (2017). Mitochondrial dysfunction and ovarian aging. Am. J. Reprod. Immunol. 77 (5). doi:10.1111/aji.12651

Wang, W., Qin, J. J., Li, X., Tao, G., Wang, Q., Wu, X., et al. (2018). Prevention of prostate cancer by natural product MDM2 inhibitor GS25: in vitro and in vivo activities and molecular mechanisms. Carcinogenesis 39 (8), 1026-1036. doi:10. 1093/carcin/bgy063

Wang, X., Fan, G., Wei, F., Bu, Y., and Huang, W. (2019). Hyperoside protects rat ovarian granulosa cells against hydrogen peroxide-induced injury by sonic hedgehog signaling pathway. Chem. Biol. Interact. 310, 108759. doi:10.1016/j. cbi.2019.108759

Wang, X. N., Zhang, C. J., Diao, H. L., and Zhang, Y. (2017). Protective effects of curcumin against sodium arsenite-induced ovarian oxidative injury in a mouse model. Chin Med. J. (Engl). 130 (9), 1026-1032. doi:10.4103/0366-6999.204927

Wang, Y., Yang, C., Elsheikh, N. A. H., Li, C., Yang, F., Wang, G., et al. (2019). HO1 reduces heat stress-induced apoptosis in bovine granulosa cells by suppressing oxidative stress. Aging (Albany NY). 11 (15), 5535-5547. doi:10.18632/aging. 102136

Wei, M., Lu, Y., Liu, D., and Ru, W. (2014). Ovarian failure-resistant effects of catalpol in aged female rats. Biol. Pharm. Bull. 37 (9), 1444-1449. doi:10.1248/ bpb.b14-00064

Wells, D. (2017). Mitochondrial DNA quantity as a biomarker for blastocyst implantation potential. Fertil. Steril. 108 (5), 742-747. doi:10.1016/j.fertnstert. 2017.10.007

Whittemore, K., Vera, E., Martínez-Nevado, E., Sanpera, C., and Blasco, M. A. (2019). Telomere shortening rate predicts species life span. Proc. Natl. Acad. Sci. U. S. A. 116 (30), 15122-15127. doi:10.1073/pnas.1902452116

Wiener-Megnazi, Z., Vardi, L., Lissak, A., Shnizer, S., Reznick, A. Z., Ishai, D., et al. (2004). Oxidative stress indices in follicular fluid as measured by the thermochemiluminescence assay correlate with outcome parameters in in vitro fertilization. Fertil. Steril. 82 (Suppl. 3), 1171-1176. doi:10.1016/j. fertnstert.2004.06.013

Wu, M., Ma, L., Xue, L., Ye, W., Lu, Z., Li, X., et al. (2019). Resveratrol alleviates chemotherapy-induced oogonial stem cell apoptosis and ovarian aging in mice. Aging (Albany NY). 11 (3), 1030-1044. doi:10.18632/aging.101808

Wu, Y., Lu, J., Antony, S., Juhasz, A., Liu, H., Jiang, G., et al. (2013). Activation of TLR4 is required for the synergistic induction of dual oxidase 2 and dual oxidase A2 by IFN- $\gamma$ and lipopolysaccharide in human pancreatic cancer cell lines. J. Immunol. 190 (4), 1859-1872. doi:10.4049/jimmunol.1201725

Xiong, S., Mu, T., Wang, G., and Jiang, X. (2014). Mitochondria-mediated apoptosis in mammals. Protein Cell 5 (10), 737-749. doi:10.1007/s13238014-0089-1

Xu, D., Hu, M. J., Wang, Y. Q., and Cui, Y. L. (2019). Antioxidant activities of quercetin and its complexes for medicinal application. Molecules 24 (6), 1123. doi:10.3390/molecules 24061123

Xu, D. P., Li, Y., Meng, X., Zhou, T., Zhou, Y., Zheng, J., et al. (2017). Natural antioxidants in foods and medicinal plants: extraction, assessment and resources. Int. J. Mol. Sci. 18 (1), 96. doi:10.3390/ijms18010096

Xu, X., Chen, X., Zhang, X., Liu, Y., Wang, Z., Wang, P., et al. (2017). Impaired telomere length and telomerase activity in peripheral blood leukocytes and granulosa cells in patients with biochemical primary ovarian insufficiency. Hum. Reprod. 32 (1), 201-207. doi:10.1093/humrep/dew283

Yadav, P. K., Tiwari, M., Gupta, A., Sharma, A., Prasad, S., Pandey, A. N., et al. (2018). Germ cell depletion from mammalian ovary: possible involvement of apoptosis and autophagy. J. Biomed. Sci. 25 (1), 36. doi:10.1186/s12929-0180438-0

Yamada-Fukunaga, T., Yamada, M., Hamatani, T., Chikazawa, N., Ogawa, S., Akutsu, H., et al. (2013). Age-associated telomere shortening in mouse oocytes. Reprod. Biol. Endocrinol. 11, 108. doi:10.1186/1477-7827-11-108

Yan, J., Deng, D., Wu, Y., Wu, K., Qu, J., and Li, F. (2020). Catalpol protects rat ovarian granulosa cells against oxidative stress and apoptosis through modulating the PI3K/Akt/mTOR signaling pathway. Biosci. Rep. 40 (4), BSR20194032. doi:10.1042/bsr20194032

Yan, Z., Dai, Y., Fu, H., Zheng, Y., Bao, D., Yin, Y., et al. (2018). Curcumin exerts a protective effect against premature ovarian failure in mice. J. Mol. Endocrinol. 60 (3), 261-271. doi:10.1530/jme-17-0214

Yang, D., Elner, S. G., Bian, Z. M., Till, G. O., Petty, H. R., and Elner, V. M. (2007). Pro-inflammatory cytokines increase reactive oxygen species through mitochondria and NADPH oxidase in cultured RPE cells. Exp. Eye Res. 85 (4), 462-472. doi:10.1016/j.exer.2007.06.013

Yang, H., Xie, Y., Yang, D., and Ren, D. (2017). Oxidative stress-induced apoptosis in granulosa cells involves JNK, p53 and Puma. Oncotarget 8 (15), 25310-25322. doi:10.18632/oncotarget.15813 
Yang, L., Lin, X., Tang, H., Fan, Y., Zeng, S., Jia, L., et al. (2020). Mitochondrial DNA mutation exacerbates female reproductive aging via impairment of the NADH/NAD(+) redox. Aging Cell 19, e13206. doi:10.1111/acel.13206

Yang, S.-G., Park, H.-J., Kim, J.-W., Jung, J.-M., Kim, M.-J., Jegal, H.-G., et al. (2018). Mito-TEMPO improves development competence by reducing superoxide in preimplantation porcine embryos. Sci. Rep. 8 (1), 10130. doi:10.1038/s41598-018-28497-5

Yang, S., Wang, J., Brand, D. D., and Zheng, S. G. (2018). Role of TNF-TNF receptor 2 signal in regulatory $\mathrm{T}$ cells and its therapeutic implications. Front. Immunol. 9, 784. doi:10.3389/fimmu.2018.00784

Yaribeygi, H., Sathyapalan, T., Atkin, S. L., and Sahebkar, A. (2020). Molecular mechanisms linking oxidative stress and diabetes mellitus. Oxid. Med. Cell Longev. 2020, 8609213. doi:10.1155/2020/8609213

Yldrm, G., Tokmak, A., Kokanal, M. K., Sarkaya, E., Züngün, C., İnal, H. A., et al. (2015). Association between some inflammatory markers and primary ovarian insufficiency. Menopause 22 (9), 1000-1005. doi:10.1097/gme. 0000000000000423

Yu, W. K., Xu, Z. Y., Yuan, L., Mo, S., Xu, B., Cheng, X. D., et al. (2020). Targeting $\beta$-catenin signaling by natural products for cancer prevention and therapy. Front. Pharmacol. 11, 984. doi:10.3389/fphar.2020.00984

Zeng, Y., Song, J., Zhang, M., Wang, H., Zhang, Y., and Suo, H. (2020). Comparison of in vitro and in vivo antioxidant activities of six flavonoids with similar structures. Antioxidants 9 (8), 732. doi:10.3390/antiox9080732

Zhang, D., Keilty, D., Zhang, Z. F., and Chian, R. C. (2017). Mitochondria in oocyte aging: current understanding. Facts Views Vis. Obgyn. 9 (1), 29-38.

Zhang, H., Davies, K. J. A., and Forman, H. J. (2015). Oxidative stress response and Nrf2 signaling in aging. Free Radic. Biol. Med. 88, 314-336. doi:10.1016/j. freeradbiomed.2015.05.036

Zhang, J. Q., Gao, B. W., Wang, J., Ren, Q. L., Chen, J. F., Ma, Q., et al. (2016). Critical role of FoxO1 in granulosa cell apoptosis caused by oxidative stress and protective effects of grape seed procyanidin B2. Oxid. Med. Cell Longev. 2016, 6147345. doi:10.1155/2016/6147345

Zhang, J. Q., Xing, B. S., Zhu, C. C., Shen, M., Yu, F. X., and Liu, H. L. (2015). Protective effect of proanthocyanidin against oxidative ovarian damage induced by 3-nitropropionic acid in mice. Genet. Mol. Res. 14 (1), 2484-2494. doi:10. 4238/2015.March.30.6

Zhang, X., Wu, X. Q., Lu, S., Guo, Y. L., and Ma, X. (2006). Deficit of mitochondriaderived ATP during oxidative stress impairs mouse MII oocyte spindles. Cell Res. 16 (10), 841-850. doi:10.1038/sj.cr.7310095

Zhang, Y., Wang, C., Jin, Y., Yang, Q., Meng, Q., Liu, Q., et al. (2018). Activating the PGC-1 $\alpha$ /TERT pathway by catalpol ameliorates atherosclerosis via modulating ROS production, DNA damage, and telomere function: implications on mitochondria and telomere link. Oxid. Med. Cell Longev. 2018, 2876350. doi:10.1155/2018/2876350

Zheng, X. W., Yang, W. T., Chen, S., Xu, Q. Q., Shan, C. S., Zheng, G. Q., et al. (2017). Neuroprotection of catalpol for experimental acute focal ischemic stroke: preclinical evidence and possible mechanisms of antioxidation, antiinflammation, and antiapoptosis. Oxid. Med. Cell Longev. 2017, 5058609. doi:10.1155/2017/5058609

Zhuang, X. L., Fu, Y. C., Xu, J. J., Kong, X. X., Chen, Z. G., and Luo, L. L. (2010). Effects of genistein on ovarian follicular development and ovarian life span in rats. Fitoterapia. 81 (8), 998-1002. doi:10.1016/j.fitote.2010.06.018

Zuo, L., Prather, E. R., Stetskiv, M., Garrison, D. E., Meade, J. R., Peace, T. I., et al. (2019). Inflammaging and oxidative stress in human diseases: from molecular mechanisms to novel treatments. Int. J. Mol. Sci. 20 (18), 4472. doi:10.3390/ ijms 20184472

Conflict of Interest: The authors declare that the research was conducted in the absence of any commercial or financial relationships that could be construed as a potential conflict of interest.

Copyright (c) 2021 Yang, Chen, Liu, Xing, Miao, Zhao, Chang and Zhang. This is an open-access article distributed under the terms of the Creative Commons Attribution License (CC BY). The use, distribution or reproduction in other forums is permitted, provided the original author(s) and the copyright owner(s) are credited and that the original publication in this journal is cited, in accordance with accepted academic practice. No use, distribution or reproduction is permitted which does not comply with these terms. 


\section{GLOSSARY}

ART assisted reproductive technology

ATP adenosine triphosphate

CAT catalase

CPM cyclophosphamide

Cyt c cytochrome c

DOR diminished ovarian reserve

FADD fas-associated death domain

GCs granulosa cells

GPx glutathione peroxidase

GPx3 glutathione peroxidase 3

GSH glutathione

GSH-Px glutathione peroxidase

GSS glutathione synthetase

Gsta4 glutathione transferase $\alpha 4$

H2O2 hydrogen peroxide

HIF1a hypoxia-inducible factor 1-alpha

HO-1 heme oxygenase-1

IFN- $\boldsymbol{\gamma}$ interferon gamma

IL-18 interleukin 18

IL-1 $\boldsymbol{\beta}$ interleukin 1 beta

iNOS inducible nitric oxide synthase

IVM in vitro maturation

LPS lipopolysaccharides

MDA malondialdehyde

Mgst1 microsomal glutathione S-transferase 1
MMP mitochondrial membrane potential

MPF maturation promoting factor

MTX methotrexate

MV Mogroside V

NAC N-acetylcysteine

NF-KB nuclear transcription factor B

3-NPA 3-nitropropionic acid

Nrf2 nuclear factor erythroid 2-related factor 2

PA Proanthocyanidin

PCOS polycystic ovary syndrome

PGC1 $\alpha$ peroxisome proliferator-activated receptor gamma coactivator 1- $\alpha$

POA postovulatory aging

POF primary ovarian failure

POI primary ovarian insufficiency

POLG polymerase subunit gamma

$\operatorname{Prdx} 3$ peroxiredoxin 3

ROS reactive oxygen species

SIRT1 nicotinamide adenosine dinucleotide-dependent deacetylase sirtuin-1

SODs auperoxide dismutases

TAS total antioxidant status

TFAM transcription factor a

tGSH total glutathione

TNF $\boldsymbol{\alpha}$ tumor necrosis factor-alpha

TNFR2 tumor necrosis factor receptor 2

TOS total oxidant status 